\title{
LA FUNDICIÓN MALINGRE DE OURENSE DURANTE EL SIGLO XIX Y SU INFLUENCIA EUROPEA
}

\section{The Malingre Foundry in Ourense during the 19th century and its European influence}

\author{
Ana María Malingre Rodríguez \\ Universidad de Vigo
}

Recibido: $31 / 03 / 20$

Aceptado: 20/06/20

\begin{abstract}
Resumen
El objeto de este artículo es tratar de explicar el origen de una industria singular y con una larga trayectoria en la ciudad de Ourense. Tratar el proceso de implementación de la Fundición Malingre de Ourense y vincularla con el proceso de industrialización que se produjo en el siglo XIX en Europa, relacionando esta fundición con la llegada a España de técnicos extranjeros, procedentes de diversos países europeos, de la mano del general Antonio Elorza.

La fundición Malingre fue la primera industria que se puede considerar como tal en la provincia de Ourense. Se estableció a mediados del siglo XIX, proporcionando a la ciudad una nueva técnica en el trabajo del hierro que propició el uso de este nuevo material aplicado a la ornamentación de edificios, embellecimiento de parques y jardines, mecanización del campo y de diversos oficios. La fábrica fue evolucionando al mismo tiempo que la ciudad hasta el ańo 1979, fecha en que cerró definitivamente.
\end{abstract}

\section{Palabras clave}

Empresa, Siderurgia, Galicia, España.

\section{Abstract}

The purpose of this article is to explain the origins of the industry in Ourense. Discuss the implementation process of the Malingre Foundry in Ourense and link it whith the industrialization process that took place in Europe in the 19th century, relating this foundry with the arrival to Spain of foreign technicians from different European countries, brought by General Antonio Elorza.

The Malingre foundry was the first industry that can be considered so in the province of Ourense. It was established in the middle of the 19th century, providing Ourense with a new technique in working iron that favoured the use of this new material applied to the ornamentation of buildings, the beautification of parks and gardens, the mechanisation of the countryside and various trades. The factory progressed at the same time as the city until 1979, when it closed down definitively.

Key words

Company, Steel, Galicia, Spain. 


\section{Introducción}

La Fundición Malingre es una industria dedicada a la fundición de hierro de segunda fusión que se estableció en la ciudad de Ourense a mediados del siglo XIX. Con hierro viejo, o con lingotes de hierro que fundía en un horno de cubilote, usando como energía carbón mineral o coque y empleando moldes que realizaba por medio de diseños propios, esta industria produjo piezas de hierro en serie y las puso al alcance del público en general.

Era esta una técnica avanzada que llegó a España procedente de Europa por la época en la que se montó la industria ourensana. Es por ello que constituye un ejemplo interesante de industria pionera, tanto dentro del panorama español en general como de Galicia en particular.

Sabemos que fueron operarios extranjeros los que trajeron esta nueva forma de trabajar el hierro a nuestro país y con este artículo se pretende profundizar en la relación existente entre Manuel Malingre Parmantier, fundador de esta fábrica, cuyo origen era belga, y los extranjeros llegados a España para la modernización de nuestra industria de fundición. Por ello, abordaremos las profesiones a las que se dedicaron sus antepasados que puedan haber influido de alguna manera en su formación, y también plantearemos la coyuntura de su llegada a nuestro país.

Finalmente incidiremos en las circunstancias que rodearon su asentamiento en Ourense y nos acercaremos al inicial funcionamiento de su fábrica y a su producción.

\section{La relación de Manuel Malingre Parmantier con los fundidores de clavos belgas del siglo XIX}

La industrialización de un país es el proceso por el que este pasa de una economía asentada en la agricultura a otra basada en la producción de bienes mediante el trabajo mecanizado y en serie, no artesanal. El trabajo manufacturado, realizado de forma artesanal, fue la forma corriente de la industria en toda Europa antes de mediados del siglo XVIII. El progreso y cambio tecnológico hacia un mundo mecanizado será lo que caracterice a las sociedades modernas y diferencie las economías desarrolladas de las tradicionales.

Esta renovación del proceso productivo no fue repentina, ni sucedió de la misma forma en todas partes. En Europa occidental se produjo en varias fases y desde las primeras zonas en las que tuvieron lugar los cambios hasta las últimas pasaron más de cincuenta años. El comienzo del proceso puede situarse en la segunda mitad del siglo XVIII en Gran Bretaña y desde allí se extendió paulatinamente al 
resto del continente. Los acontecimientos no fueron súbitos, sino que poco a poco fueron sucediéndose una serie de circunstancias que propiciaron un nuevo modo de producción que llevó a Europa a una transformación de su economía, con importantes consecuencias a largo plazo.

A finales del siglo XVIII Gran Bretaña llevaba un considerable adelanto respecto a los países del continente. Los avances técnicos llevaron consigo un aumento de producción, además de transformaciones paulatinas en la forma de vida. El ritmo de los diferentes países europeos a la hora de imitar a los británicos no fue uniforme. Los historiadores Villares y Bahamonde establecen tres grupos de países: en un primer grupo estarían Bélgica, Francia y Alemania; un segundo grupo de países que se incorporaron ya avanzado el siglo XIX, como Escandinavia, Hungría o Rusia; y, por último, un tercer grupo constituido por la zona periférica de Europa, entre la que se encuentran los Balcanes y el Mediterráneo, aunque con excepciones como el norte de Italia, Cataluña o el País Vasco. ${ }^{1}$ A Galicia podríamos incluirla también en ese grupo de la periferia.

El país del continente europeo que dio entrada al proceso, tras Gran Bretaña, fue Bélgica y esto se debió a su privilegiada situación geográfica y a sus recursos energéticos. Así, la mayoría de los autores coinciden en situar el comienzo de la industrialización entre 1800 y 1830, en la provincia que denominamos Henao (Hainaut en francés), en la Región de Valonia, donde se encuentra la ciudad de Charleroi, y cuya capital es Mons. Se trata de una zona con gran tradición en el trabajo del hierro, en la que era habitual fundirlo mediante carbón vegetal de leña y trabajarlo con la ayuda de la fuerza hidráulica disponible. Casi todo el trabajo se llevaba a cabo en empresas familiares y el producto elaborado constituía el ramo más importante en las exportaciones. ${ }^{2}$

Pero lo que hizo que Bélgica se adelantara al resto del continente fue la rápida asunción de las tecnologías inglesas. En 1821 se puso en marcha el primer horno de pudelado y comenzaron los experimentos para el uso del coque, siendo Cockeril en el año 1826, en la ciudad de Searing, quien consiga poner en marcha el primer alto horno que funcionaba con coque.

La industria belga logró adaptarse rápidamente a las modernas técnicas inglesas de la mano de expertos procedentes de Gran Bretaña que, poco a poco, fueron reemplazados por trabajadores locales quienes, a su vez, se convirtieron en expertos en estas nuevas tecnologías. De esta forma, Bélgica desarrolló su metalurgia y la fabricación de una maquinaria apropiada.

1 Villares Paz y Bahamonde Magro (2015), pp. 34-39.

2 Pirenkemper (2001), pp. 30-37. 
La metalurgia, ese sector en el que los belgas trabajaban desde antaño, a través de talleres familiares dedicados a la fundición de clavos (cloutier) para la construcción de barcos en ciudades de Holanda especializadas en industria naval (como Amsterdam, la zona de Frisia, Gelderland, Utrecht, etc.) llega a ser, a comienzos del siglo XIX, el ramo más importante en las exportaciones del país. Hacia 1830, en gran parte por las dificultades producidas con la independencia de Bélgica, comienza a decrecer la explotación de clavos, sector al que se dedicaba gran parte de los fundidores de esa zona.

El 21 de noviembre del año 1834 nació en este país, en la región de Valonia, Emmanuel Malengret (Malingre) Parmentier, quien años más tarde creó la Fundición Malingre en Ourense (1864-1979). Su localidad natal fue Souvret, pequeño municipio del ayuntamiento de Courcelles, distrito de Charleroi.

En la transcripción de su partida de nacimiento, traducida del francés, podemos ver claramente cuál era la profesión de su padre, Casimir Joseph Malengré, de 27 años: fabricante de clavos. (Anexo 1). ${ }^{3}$

Casimir Joseph Malengré nació en 1807 en el municipio de Chapelle lez Hairlaimont, muy cerca se Souvret. El lugar, aunque actualmente es Bélgica, en la época de su nacimiento pertenecía a Francia. Fue probablemente uno de esos fabricantes de clavos que por el año 1834 vio como decaía su profesión, oficio al que también se había dedicado su padre, Jaques Malengrez. Conocemos la profesión de Jaques, natural de Souvret y fabricante de clavos, a través de su partida de defunción, hecho que se produjo el 8 de agosto de 1827, cuando contaba con 50 años en el hospital de la villa de Sn. Venant (Anexo 2). ${ }^{4}$

\section{La llegada a España de la familia Malingre Parmantier}

Sabemos que al tiempo que la industria de clavos belga perdía su hegemonía al disminuir la demanda por parte de los constructores de barcos holandeses, Francia demandaba a Bélgica personal instruido en fundición. Entre esta mano de obra belga, avezada en el oficio de fundir, se encontraba Casimir Malengré.

Francia, como Gran Bretaña, desarrolló durante el siglo XVIII algunos inventos, pero no tuvieron la misma repercusión que los británicos. Los franceses se esforzaron, con lentitud y retraso, en imitar a los ingleses, pero tardaron un poco más en industrializarse. ${ }^{5}$

3 Archives de l'État à Mons, Bélgica, Registro de nacimientos, año 1834, n. ${ }^{\circ} 30$.

4 Archives municipio de Sn.Venant, Paso de Calais. Francia. Extracto del registro de las actas de fallecimiento 1827.

5 Godechot (1981), p. 84 
La transformación de la industria francesa cobró especial intensidad en el periodo comprendido entre 1830 y 1850 . Por eso se dice que fue una industrialización tardía. Hasta mediados del siglo XIX no se estableció una industria siderúrgica con éxito, salvo en algún enclave que desarrolló talleres de laminado y de pudelado. Pero lo que motivó que en Francia comenzara una gran demanda de productos de hierro fue la construcción del ferrocarril a partir de mediados de siglo, fecha en la que el país importó máquinas y también personal experto de Inglaterra y Bélgica. Casimir Malingre (como se empezó a escribir su apellido) estuvo entre esos trabajadores del norte que llegaron a trabajar al sur de Francia. Sabemos que entre 1843 y 1849 la familia Malingre Parmantier vivía en Alès, departamento de Gard, en Occitania. Este dato se desprende de las partidas de nacimiento de los hijos menores de Casimir Malingre.

En Alès (Alais en castellano) existió por esa época una fundición denominada Industrias Tamaris, y allí trabajó Casimir. Así lo indica la partida de nacimiento de su hija pequeña, Enriqueta: “...comparece el señor Casimir Malingré, fundidor en la Fábrica de Tamaris, domiciliado en esta comunidad; el cual me presenta una niña, de sexo femenino, nacida esta mañana a las 10 horas en la casa que él habita, en el barrio de Brouzen." 6

Gard es un departamento del sureste de Francia, limítrofe con el de Abeyron donde en el año 1852 reside la familia Malingre, dato que conocemos por el contrato de trabajo por el que Casimir llega a España y que comentaremos más adelante.

A pesar de que España va a la zaga de Francia (de Europa, en general) en el tema industrial, existió un lugar muy importante y pionero en la industrialización del país: la Fábrica de Armas de Trubia, Asturias.

Aunque a finales del siglo XVIII había en España varias fábricas militares, la Secretaría de Guerra fue sustituyéndolas, poco a poco, por la Fábrica de Armas de Trubia. La elección del lugar se debió a la existencia en el lugar de recursos forestales y a la facilidad de transporte que proporcionaba el río Nalón. En esta fábrica se intentó aplicar el coque al horno alto, pero el resultado no fue el deseado y se volvió al combustible vegetal hasta 1808, año en que la invasión francesa paralizó los trabajos, ${ }^{7}$ al ser ocupadas las fábricas, que entraron en un declive del que ya no consiguieron salir, siendo abandonadas en $1830 .^{8}$

Posteriormente, el Gobierno vio la necesidad de contar con una adecuada industria de armas en el país y solicitó al General Elorza que realizase una memoria en la que expusiera el estado de la fábrica y las medidas que, en su opinión, deberían

6 Archives municipales d`Alès, Naissances 1849, CD6, apunte 144, p. 45.

7 Suárez (1995), pp. 207-223.

8 Alcalá-Zamora (1974), pp. 22-24. 
tomarse para modernizarla. La memoria se tituló: Lo que es la fábrica de Trubia y lo que de ella se puede y debe esperar con la protección del gobierno de Su Majestad. Poco después, por Real Orden, el General Elorza fue nombrado director, con el planteamiento de adquirir terrenos, demoler instalaciones inservibles y ruinosas, aumentar las dimensiones del canal que iba a proporcionar energía hidráulica, adquirir minas de hierro y de carbón coquificable, construir puentes, facilitar la explotación de calizas, arcillas y arenas de moldeo, viajar por los países europeos tecnológicamente más avanzados donde reconsiderar la fabricación del hierro colado de artillería, adquirir maquinaria y contratar a maestros extranjeros, construir naves de moldeo, construir hornos altos, montar cubilotes para obtener hierro de segunda fusión, etc.. ${ }^{9}$

Esta fábrica de armas era, a mediados del siglo XIX, la instalación siderúrgica con los mejores medios de producción de España, pero parece que tuvo gran dificultad para encontrar obreros. Elorza se encontró con el problema de falta de capital humano para llevar a cabo los trabajos que, con la modernización, eran necesarios. Esta dificultad era común para toda la industria del hierro.

El nombramiento de Elorza fue una decisión acertada, pues debido a sus estudios y a los diversos viajes que había hecho por Europa con el fin de ilustrarse en la ciencia y tecnología de interés para su profesión, se había convertido en uno de los ingenieros industriales más capacitados del momento. Además, al haber estado exiliado por problemas políticos en varios países extranjeros (como en Francia, Bélgica, Piamonte e Inglaterra), tenía conocimiento de lo que se hacía por Europa en materia de fundiciones. Con este bagaje de conocimientos, durante su periodo en la dirección de Tubia abrió una escuela de formación profesional para obreros en la propia fábrica. Se inauguró en el año 1850 y llegó a tener tanto éxito que sirvió de modelo a otras ciudades. Parece que Trubia fue una de las escuelas de aprendices más antiguas de España. Creó esta con el objetivo de disponer, en un futuro, de personal cualificado para que la industria se pudiera valer por sí misma sin recurrir a extranjeros a los que él mismo tuvo que traer a España con un elevado jornal. Escribió: "Cuando tenga obreros que desempeñen función de maestros, mandaré a los extranjeros a sus países al término de sus contratos”. En esta dinámica, sabemos, por Julio Tascón y Germán Ojeda, que entre 1855 y 1863 Elorza trajo a España a 49 fundidores de origen belga y otros operarios especializados, con contratos de 3 años. "En pocos años se logró formar en Trubia un grupo de operarios inteligentes y laboriosos a la par que honrados e instruidos ciudadanos". ${ }^{10}$

9 Arias y Suárez (2008), pp. 5-6.

10 Tascón y Ojeda (2000), p. 16. 
Entre las innovadoras medidas puestas en marcha por Elorza, tuvo una profunda influencia el conocimiento que había adquirido en la industrialización belga, hasta tal punto que el influjo de ese país y en particular el valón, se dejó sentir sobre la arquitectura industrial y los espacios de vivienda de obreros que, bajo la dirección del general, fueron promovidos en Trubia. ${ }^{11}$

Pero según documentación de la propia fábrica, hay constancia de que, ya antes de esa época, el general Elorza había iniciado la contratación de especialistas extranjeros para trabajar allí, técnicos cualificados en diferentes materias, con experiencia y que podían traer a Trubia procesos innovadores para la mejora de los productos.

\begin{tabular}{|c|c|c|c|}
\hline \multicolumn{5}{|c|}{ Cuadro 1. Algunos técnicos extranjeros contratados para trabajar en la fábrica de Trubia } \\
por Francisco de Elorza
\end{tabular}

11 Díaz y Niembro (1999), p. 40.

12 Salvo donde se indica otra cosa, se debe suponer que ya estaban trabajando con anterioridad en la fábrica.

13 Falleció en accidente de trabajo en la mina donde trabajaba.

14 Fecha de su contrato.

15 Fecha de su contrato.

16 Fecha de rescisión de contrato. 


\begin{tabular}{|c|c|c|c|}
\hline Fecha & Categoría laboral & Nombre & Natural de \\
\hline Id. & Calentador hornos & Jacobo Nicea & Prusia \\
\hline 08.07 .1856 & Contramaestre & Juan Jonquet & - \\
\hline Id. & Maestro barrenador & Felipe Maitre Jean & - \\
\hline 27.02 .1857 & Maestro ladrillos & Manuel Fojsoul & Bélgica \\
\hline 23.07 .1886 & Maestro fundición & Juan Jonquet & - \\
\hline Id. ${ }^{17}$ & Maestro & Francisco Bertrand Hatot & Bélgica \\
\hline
\end{tabular}

Fuente: fotocopia que conserva el ingeniero de minas, Ricardo Arias Sarasola, procedente de las actas de la Junta facultativa de la Fábrica de Armas de Trubia, documentación a la que tuvo acceso hace muchos ańos en el archivo de la propia fábrica.

De entre estas personas, conocemos el caso de Denis Thiry Delmalle, quien posteriormente participó en importantes proyectos industriales en la región, como es la Real Compañia Asturiana de Minas en Arnao (de capital belga) y que, además, impulsó sus propios negocios, como la Fábrica de pólvora y dinamita de la Manjoya en la década de 1860 o la explotación de mineral de hierro en Naranco, en los años 70 de la misma centuria. Se trata de una figura con perfil técnico convertida en emprendedor. Es posible que alguno de los demás tuviera también recorrido fuera de la fábrica de Trubia. En el caso de Casimir Malingré sabemos que no tuvo tiempo de desarrollar trabajo fuera de Trubia, pues no vivió mucho tiempo, ya que falleció en la propia fábrica de armas a los pocos años de su ingreso.

Su contratación se produjo a raíz de que el General Elorza, en sesión de la Junta facultativa de la Fábrica de Armas de Trubia, el 16 de Julio de 1852, en calidad de director de la fábrica planteó "la necesidad de contratar al maestro fundidor de altos hornos Mr. C. Malingré para que se encargue de los hornos altos de esta fábrica y la Junta convencida de la necesidad que tiene la fábrica de este operario acordó se atendiera su contrata." 18

El contrato de Casimir Malingré es el motivo por el que este trabajador belga llegó a España en compañía de su familia. En el contrato se explican detenidamente las características del trabajo, que consistiría en ejercer de maestro fundidor de los altos hornos en la Fábrica de Armas de Trubia. Tendría a su cargo la vigilancia de los operarios fundidores, los cargadores y todos los empleados de la zona de minerales y de carboneras. Aportaría al capataz los datos diarios del funcionamiento de los altos hornos, que tendría que vigilar, y enseñaría a los obreros que tuviera a sus ór-

17 Fecha de su retiro. Fue socio de Elorza en negocios comunes.

18 Archivo particular de Ricardo Arias Sarasola. Acta n. ${ }^{\circ} 55$ de la Junta facultativa de la Fábrica de Armas de Trubia. Sesión de 16 de julio de 1852. [Fotocopias del original del Archivo de la fábrica]. 
denes. También se referencian las condiciones del trabajo: el abono de los gastos del desplazamiento a España, tanto a él como a su familia, así como los de regreso a su país. Y las prestaciones a las que tendría acceso: combustible para su cocina, aceite y muebles y, en caso de enfermedad, tendría médico y medicinas para él y su familia. Y el sueldo diario se le abonaría desde el día de su partida desde Francia y lo mismo a su regreso. Se trataba de un contrato por cuatro años. Se daría un aviso 3 meses antes de terminar, bien para su renovación, o para su finiquito. (Anexo 3).${ }^{19}$

Leyendo detenidamente el contrato, vemos que Casimiro no lo firma, ni nadie en su lugar, porque probablemente todavía no está en Trubia cuando se redacta el documento:

El Sr. Presidente manifestó la necesidad de contratar al maestro fundidor de los Hornos Altos Mr (la r está arriba, no abajo, o sea en monsieur no mister) C. Malingre, de Bromma(n/r)t, en el Departamento del Aveyron (Francia), para que se encargue de los Hornos Altos de la Fábrica, y la Junta, convencida de la necesidad que tiene la Fábrica de este operario, acordó se extendiera su contrata bajo las condiciones siguientes: $1^{\mathrm{a}} \mathrm{El} \mathrm{Sr}$. Malingre se compromete a pasar a España para trabajar como […].

Sabemos que en el año 1856 se prorrogó el contrato, tras ser acordada la necesidad de su renovación en sesión de la Junta facultativa de 8 de julio de ese año. En él se establecían las condiciones bajo las cuales Casimiro Malingre se obligaba a continuar trabajando en esta fábrica como maestro fundidor de altos hornos en las mismas circunstancias que estaba, con obediencia al director y a los oficiales de la fábrica. Esta vez se hace hincapié en que enseñaría el oficio con celo e interés a los operarios del país que tuviera a sus órdenes. Se estipula el sueldo además de las prerrogativas de las que ya disfrutaba en el otro contrato y quedan reflejadas las condiciones del viaje de vuelta que tendrá la familia para regresar a su país. (Anexo 4). ${ }^{20}$ Sin embargo este contrato de prórroga duró poco más de un año, ya que Casimiro murió en Trubia el 25 de noviembre de 1857, siendo enterrado en el cementerio de la propia fábrica. El acta de defunción hace alusión a los seis hijos que dejaba a su muerte. (Anexo 5). ${ }^{21}$

19 Archivo Particular de Ricardo Arias Sarasola. Acta n. ${ }^{\circ} 55$ de la Junta facultativa de la Fábrica de Armas de Trubia. Sesión de 16 de julio de 1852. [Fotocopias del original del Archivo de la fábrica].

20 Archivo particular de Ricardo Arias Sarasola. Acta n. ${ }^{\circ} 51$ de la Junta facultativa de la Fábrica de Armas de Trubia. Sesión de 8 de julio de 1856, fol. n. ${ }^{\circ}$ 154. [Fotocopia del original del Archivo de la fábrica].

21 Archivo Eclesiástico del Ejército. Libro 1201. Folio 35. Acta n. ${ }^{\circ} 33$. 


\section{Manuel Malingre Parmantier se establece en Ourense}

El padre de Manuel Malingre muere en Trubia, pero algunos de sus hijos no se van de España. Uno de los que se quedó para siempre fue su hijo Manuel (Emmanuel), quien sabemos que había contraído matrimonio, un mes antes de morir su padre, con Inés Ludeña Álvarez, el día 10 de octubre de 1857, en la ciudad de Gijón. ${ }^{22}$ En el acta de matrimonio aparece ya con su nombre españolizado, Manuel Malingre Parmentier.

Inés Ludeña Álvarez- Laviada (así es como aparece en algunos documentos) nació en Gijón (Asturias) el 21 de enero de 1835. La fecha de nacimiento consta en los padrones de vecinos de la ciudad de Ourense de los años 1872 y $1873 .{ }^{23}$

Desconocemos la dedicación profesional que tuvo Manuel Malingre en Gijón, aunque pensamos que pudo llegar a la ciudad por alguna actividad relacionada con la profesión de fundidor. Sabemos que Gijón, por esa fecha, estaba en pleno desarrollo debido, en parte, a la entrada en funcionamiento del ferrocarril de Langreo y a la potenciación de la cuenca carbonífera del Valle del Nalón, circunstancias que favorecieron su desarrollo económico y territorial. Allí estaban localizadas la mayor parte de las empresas relacionadas con la extracción y comercialización de la hulla. Muchas de esas compañías eran dirigidas por técnicos y comerciantes extranjeros (belgas, franceses e ingleses), quienes iniciaron el proceso industrial gijonés. Este fue el caso de la Fundición La Begoñesa, constituida en 1857 por los belgas Julio Kesler y Chirstian D.L. Frederix, junto a media docena de comerciantes locales, entre los que se encontraba Juan Díaz Laviada. ${ }^{24}$ Por este motivo, la fundición se llamó años después, Laviada y Cía. Apuntamos este dato por ser belgas los emprendedores y por el apellido Laviada, pues sin poder demostrar nada, intuimos que pudiera tener alguna relación con la presencia de Manuel en Gijón.

En 1858 Manuel Malingre continuaba viviendo Gijón, pues su primer hijo, Casimiro Malingre Ludeña, nació en esta misma ciudad el 14 de agosto de 1858, a las dos de la madrugada en la calle de los Moros o $\operatorname{Muros}^{25}$ y ese mismo día fue bautizado en la iglesia parroquial de San Pedro. ${ }^{26}$ En algún momento, a partir de esa fecha, Manuel toma la decisión de asentarse en Ourense (Galicia), ciudad en la que sabemos con seguridad que estaba instalado en 1864.

22 Archivo Municipal de Gijón. Registro Civil. Libro de matrimonios de 1857, nº 63, p. 38

23 AHPO Concellos. C-530. Año 1872. Calle Santo Domingo y Concellos. C-534. Año 1873. Calle Santo Domingo. $5^{\circ}$ cuaderno.

24 Llordén, (1994), p. 19.

25 Archivo Municipal de Gijón. Registro Civil. Libro de nacimientos de 1858, n. ${ }^{\circ}$ 249, p. 134.

26 Archivo particular de la familia Freijanes Malingre. Certificado de Bautismo expedido en la parroquia de San Pedro Apóstol de Gijón el 27 de agosto de 1895 por D. Cipriano Fernández y Robledo. Libro de bautismos XVII, folio 236. (Ver en apéndice documental, n. ${ }^{\circ}$ 2). 
Galicia era un territorio situado en el extremo noroccidental de la península que, en aquella época, estaba muy mal comunicado con el resto de España y con características lingüísticas y culturales propias. Una región que vivía fundamentalmente del campo, con una agricultura de consumo que, en las zonas costeras, combinaba con actividades relacionadas con la pesca y el marisqueo.

Durante el siglo XVIII existían una serie de actividades artesanales textiles, curtidores, zapateros, saladores de pescado, canteros, mamposteros, herreros, cordeleros, alfareros o papeleros, cuya producción se comercializaba hacia otras regiones. Hubo alguna iniciativa empresarial singular para el contexto de la época, como fue la construcción de un alto horno destinado a la fundición de hierro en Sargadelos, el primero de ámbito civil en España. También tuvieron importancia las fábricas de harinas o algún proyecto de gran calado como la fábrica de cobre en Xubia, o la de tabacos en A Coruña. Pero, aunque existió una aceptable actividad manufacturera para la época, no tuvo Galicia la ventaja de vascos y catalanes, ni los recursos naturales para consolidar una industria moderna.

La Galicia interior mantenía un pequeño comercio de ganado vacuno con Portugal y Castilla y la emigración estacional de segadores gallegos a Castilla y Andalucía, en los meses de verano, propiciaba la comercialización de productos elaborados en Galicia. ${ }^{27}$ Por ejemplo, los lienzos que se producían en el mercado regional eran distribuidos por arrieros y emigrantes estacionales, quienes financiaban de este modo sus desplazamientos a las siegas, tejiendo una red de intercambios. Pero los catalanes acapararon el mercado textil español al introducir los avances procedentes de Gran Bretaña y desbancaron esta industria artesanal gallega.

En las zonas costeras la actividad artesanal de salazón de pescado poco a poco dejó de estar en manos de la gente de los pueblos, y fue apareciendo, especialmente en las Rías Baixas y a finales del siglo XVIII, un grupo de personas de negocios (muchas veces de origen catalán) que se dedicaron a exportar salazón a Portugal y a algunas zonas del Cantábrico. ${ }^{28}$

El sector de los curtidos, que también había sido importante en Galicia, decayó en el conjunto del Estado hacia mediados del siglo XIX debido a las nuevas técnicas que iban surgiendo en otros países. La nueva forma de conseguir el ácido tánico, fundamental para acelerar el proceso de curtido, y hasta entonces solo conseguido a partir del roble, fue una de esas técnicas novedosas con las que se conseguía más producción con mayor rapidez. Cataluña fue una de las zonas que consiguió traer producto del extranjero y comercializarlo. ${ }^{29}$

27 Carmona y García (1985), pp. 433-452.

28 Alonso (2005), pp. 37-40.

29 Carmona (1990), pp. 29-32. 
Así, y quizá por todo esto, según opina Nadal, a mediados del siglo XIX Galicia era un territorio mucho menos industrializado que otros lugares de España, representando muy poco en la historia de la industrialización, llegando a estar incluso a la cola, solo por delante de Canarias. ${ }^{30}$

Tampoco existía en la región un comercio estable, pues se trabajaba con un sistema de ferias que propició la existencia de mucho comercio ambulante. Al revisar la documentación del AHPO, en los libros de industria-hacienda de la época podemos ver muchos vendedores ambulantes en Ourense. Incluso existe un registro de estos profesionales de entre los años 1864 y1865 procedentes de toda España, así como de diferentes pueblos de Galicia. ${ }^{31}$

Sin embargo, frente a esa idea, mayoritaria en la bibliografía y que concibe cierto pesimismo por la poca industrialización de Galicia, existe un trabajo que cuestiona, por un lado, la imagen de una región escasamente industrial y, por otro, arrincona el tópico de la falta de iniciativa empresarial de los gallegos. ${ }^{32}$ Sabemos que el sector conservero se consolidó hacia finales del XIX como el primer sector propiamente industrial en Galicia, movilizando cantidades importantes de mano de obra asalariada y utilizando técnicas modernas. Y contribuyó al avance de otros sectores, como la construcción de envases, la metalografía, los talleres de construcción y la reparación de accesorios, maquinaria y otros útiles de fabricación (parrillas, hornos, llaves para envases), fábricas de hielo, etc. ${ }^{33}$

La pujanza alcanzada por este sector hizo que los estudios bibliográficos referidos a la industrialización gallega se dedicasen a explicar fundamentalmente esta cuestión y no pusieran mucho esfuerzo en investigar la situación de la industria del hierro en Galicia. A esto hay que añadir que la mayoría de las fundiciones gallegas desaparecieron del panorama industrial en los años 70 y 80 y al ser los estudios referentes a la industrialización a partir de esta fecha no repararon en profundizar demasiado en este tipo de industria.

Este tipo de actividad, la fundición de segunda fusión, se estableció en territorio gallego a partir de mediados del siglo XIX. Hasta entonces el hierro se producía en las ferrerias, donde se elaboraba también hierro dulce siguiendo un procedimiento directo. Estas se encontraban situadas en lugares frondosos y a orillas de los ríos, para tener asegurado el suministro de leña que servía de combustible y la energía de las corrientes. Las ruedas hidráulicas movían barquines o fuelles encargados de mantener el fuego del horno, y los mazos compactaban la masa de hierro resultante de la fusión de la calcinación de la vena en los hornos.

30 Nadal y Carreras (1990), pp. 23.

31 AHPO, libros Industria-Hacienda, n. ${ }^{\circ}$ 2.449, 2.983, 3.000, 3.001.

32 Carmona y Nadal (2005), p. 444.

33 Carmona y García (1985), pp. 442-445. 
Posteriormente los herreros trabajaban de forma artesanal el hierro y lo transformaban, mediante forja, en útiles. Los establecimientos en los que trabajaban los herreros solían estar situados en el casco de las poblaciones, en pequeñas instalaciones muchas veces ubicadas en el bajo de una casa, vivienda del propio trabajador. Dotadas de un hogar y un barquín, movidos a mano. Este tipo de instalaciones podían ser el lugar de trabajo de herreros, cerrajeros, cuchilleros, etc. Su función era abastecer la heterogénea demanda de los habitantes de las villas y de los campesinos, para los que fabricaban flejes, rejas, aperos de labranza, etc. ${ }^{34}$

Para cualquier pieza de hierro que hubiera que construir, había que obtener el hierro en una ferrería. En estos establecimientos conseguir un kilo de hierro implicaba utilizar unos 30 kilos de madera. Estas ferrerías estaban, por ese motivo, en lugares cercanos a bosques de hayas, robles o montes bajos de brezos.

Ya en el siglo XVII, en Gran Bretaña, Lord Dudley había logrado sustituir la madera al utilizar hulla como combustible para la fabricación de fundición, aunque con dificultades por la obstrucción al paso de los gases y los problemas ambientales asociados. Así que tuvieron que pasar años, hasta que en 1709 Abraham Darby consiguió utilizar coque como combustible en las fábricas de Coalbrookdale (Inglaterra), con completo éxito. El coque se obtenía de carbonizar la hulla y permitía elaborar el hierro con menos costes y, sobre todo, en lugares alejados de los bosques. Esto constituyó un gran avance y contribuyó a la Revolución Industrial. El cambio de combustible fue produciéndose poco a poco en Europa y no se generalizó hasta casi un siglo después, en los años 60-70 del siglo XIX, ${ }^{35}$ fecha en que se comenzó a aplicar el hierro fundido a la construcción de edificios y elementos ornamentales.

Debemos referirnos al descubrimiento del horno de cubilote en Francia alrededor de 1720, aunque la primera patente de este tipo de horno fue del inglés John Wilkison en el año 1794. Se trata de un horno para fundir hierro en una segunda fusión. "Este horno se puede considerar otra aportación de la Revolución Industrial y sustituía el uso del carbón vegetal por el coque metalúrgico.”36 Este tipo de horno cobró importancia, pues permitía fundir varias veces al día, o bien una o dos veces por semana, mientras que el horno alto debía de funcionar ininterrumpidamente. ${ }^{37}$ Además estos hornos serían idóneos para la fundición de segunda fusión, sobre todo a partir de que se empezó a usar el coque como fundente. El mineral líquido, que se producía en este horno se solidificaba al enfriarse, tras volcarse en los moldes. Una vez solidificado, se separaba del molde (desmoldeo), sometiendo

34 Carmona y García, (1985) pp. 442-445.

35 Bilbao (1988), p. 228.

36 Matute (2005), pp. 299-302.

37 Vázquez (1995), p. 50. 
el objeto resultante a una operación de limpieza y desbarbado, después se procedía al mecanizado de la pieza en un taller específico. ${ }^{38}$

La elaboración de los moldes requería un diseño previo, inherente al propio proceso de fabricación. Esto solía hacerse a partir de dibujos, que debían aumentar las medidas del modelo, para corregir la contracción que se producía en el hierro al solidificarse. Se hacía un modelo que si era de madera había que lijar para mejorar su acabado y eliminar o redondear aristas. Este se encajaba en una superficie de arena y se apisonaba. La combinación del cubilote y la moldería propició la proliferación de fundiciones de segunda fusión de hierro a lo largo del continente europeo. Y con un modelo se podía repetir misma pieza las veces que se quisiera. El cubilote, funcionando con coque, permitía fundir hierro viejo o lingotes, para poder elaborar productos de forma industrial. ${ }^{39}$

Durante el siglo XIX proliferaron las fundiciones con hornos de cubilote que con coque fundían hierro de segunda fusión. ${ }^{40}$ Estas fundiciones no necesitan tener cerca una fuente de energía ni estar situadas en los bosques.

En Galicia la primera fundición que se montó fue la de Sargadelos. Estaba próxima a la fraga de A Rúa, en la Mariña lucense, muy cerca del mineral de hierro que se extraía en Reinante y otras feligresías. ${ }^{41}$ En mayo de 1788 se solicitó una real licencia para montar una fábrica que produjera ollas o potes de hierro. En esa fábrica se fundiría hierro y se elaborarían piezas con moldes, pero no usaba hierro de segunda fusión, sino que elaboraba el hierro en su ferrería. En 1791 por medio de una Real Cédula, se montó un horno (para fundir hierro en primera fusión), usando madera como energía y muy pronto otro de reverbero (para fundir los lingotes) y posteriormente modelar cañones, bombas o granadas. A pesar de que la licencia inicial era para una fábrica de ollas, la fundición de Sargadelos fundamentalmente se dirige al mercado militar, actividad a la que se dedicó en exclusiva durante los años siguientes, ${ }^{42}$ abasteciendo al ejército de municiones: balas de metralla y granadas, reorientando su producción a la fabricación de pedidos para el ejército. Y pasó a denominarse Real fábrica de Municiones. ${ }^{43}$ A partir de 1816 amplió las instalaciones.

En los años 40 del siglo XIX, la Fábrica de Armas de Trubia con la dirección del general Elorza, utilizó métodos mucho más modernos, como el uso del coque y

38 Matute (2005), pp. 298-303.

39 Urdangarín e Izaga (2018), [en línea].

40 Díez (2013), p. 50.

41 Otero (2009), [en línea].

42 Carmona (1993), p.13-16.

43 Martul y Varela (2009), pp. 194-196. 
en cambio Sargadelos continuó usando carbón vegetal todavía entre 1853 y $1858 .{ }^{44}$ Es posible que se hiciera un intento de uso de coque, procedente de Asturias, pero, de ser así, debió ser muy puntual, ${ }^{45}$ con lo que era poco competitiva. Además, al no pasar por allí la red ferroviaria, quedó alejada e incomunicada de los grandes centros de producción.

Esto lo aprovecharán otras industrias en esa época en Galicia, lo que lleva a Sargadelos a su desaparición y cierre definitivo en $1875 .{ }^{46}$

A mediados del siglo XIX se instalan en Galicia fundiciones de segunda fusión de hierro, o lo que es lo mismo, la industria moderna del hierro. Algunas de ellas continuaron en plena actividad pasada la mitad del siglo XX. Las nuevas fábricas se situaron en lugares en que se suponen con posibilidades para desarrollar una gran actividad mercantil o sitios en los que comienzan a desarrollarse otras industrias, también en zonas cercanas a las vías de comunicación del momento.

Nos encontramos, además, en una época en la que están cambiando las necesidades de la sociedad. Crecen las ciudades, fruto de diversos procesos como el avance del comercio, el desarrollo de la incipiente industria, la aparición de nuevas clases sociales que demandan nuevas viviendas, los nuevos medios de comunicación, etc.

La respuesta a estas necesidades vino muchas veces de la mano de las nuevas fundiciones, que dieron soluciones como las traídas para las aguas, la ornamentación de parques y jardines, el embellecimiento de fachadas e interiores de los edificios con barandillas de balcones, balaustres de escaleras o columnas de hierro, galerías, bajantes o cubrecaños. La propia iluminación conllevó también cambios: desde el aceite o el petróleo a la electricidad, y las nuevas farolas y columnas serán también realizadas en las fábricas de fundición. Es decir, que los productos elaborados en las fundiciones tendrán una gran cantidad de aplicaciones en esa época y primeros años del siglo XX.

Del mismo modo, por estas fechas se experimentarán muchos cambios ligados a la producción agrícola que incidirán en la demanda de diferentes tipos de piezas. Aquí también entran las fundiciones.

Además, la paulatina industrialización conllevaba la necesidad de piezas y de talleres de reparación para estas. Las fundiciones de ese momento solían acoplar talleres de mecanización de las piezas que realizan y también servían para cubrir las necesidades de reparación de otras industrias. En este momento de cambios las fundiciones suponen la posibilidad de avance y desarrollo.

44 Otero (2009), [en línea].

45 Bas (2009), pp. 275-280.

46 Carmona (1990): pp. 26-27. 
Esta situación de Sargadelos, quedando al margen de la construcción del ferrocarril y los cambios que se estaban produciendo en las ciudades españolas de la época propiciaron que, Manuel Malingre Parmantier viera posibilidades de futuro con este tipo de industria y decidiera su establecimiento en Ourense alrededor de 1864, probablemente animado por el paso del ferrocarril por esta ciudad. Así establece su negocio en la ciudad auriense, donde esta fábrica quedará instalada desde esta fecha, hasta el año 1979. Y al frente de la misma, sin interrupción, tres generaciones de la familia Malingre. ${ }^{47}$

\section{La primera fundición de hierro de Ourense}

Manuel Malingre Parmantier se dedicó al oficio de fundir desde joven, y con sus antecedentes familiares, una estirpe de fundidores europeos, conocía los entresijos de este tipo de actividad de primera mano. Como vimos, su abuelo Jacques y su padre Casimiro Malingré, fueron fundidores de clavos en Bélgica. Su padre, además, fue también maestro de fundición en Francia, en Industrias Tamaris, y llegó a España como maestro de fundición a la Fábrica de Armas de Trubia. Incluso existe la posibilidad de que Manuel pudiera haberse formado en la entonces incipiente Escuela de aprendices de Trubia. Su pasado ligado al hierro fue trascendental para tomar la iniciativa y decidirse a montar una industria moderna en Ourense.

Con su trayectoria, Manuel Malingre llegó a ser un personaje distinto e interesante. Desarrolló las nuevas técnicas montando una fundición que tendrá continuidad en las dos generaciones siguientes. Pero no se conformó con crear su propia fundición con la que desarrollar su oficio, sino que, además, a lo largo de su vida llevó a cabo otro tipo de experiencias relacionadas con el mundo industrial de la época: fue propietario de varios molinos harineros y llegó a producir electricidad para su fábrica. De su fundición se dice que "fue la única industria que verdaderamente puede recibir tal nombre a comienzos de siglo en Ourense."48

Según la tesis doctoral de Vázquez Vaamonde, la fundición se instaló en Ourense en 1865, denominándose La primera de Orense. ${ }^{49}$ Ciertamente sabemos que el 6 de marzo de 1865 ya existía en Orense una fundición de hierro de Manuel Malingre denominada La primera en Orense porque en esa fecha un administrador de rentas de Vigo, Donato Hevia Argüelles, le facilita un préstamo de capital para

47 Malingre (2011), p. 243-246.

48 Somoza (2000), p.118.

49 Vázquez (1995), p. 549. 
la fábrica ya existente. ${ }^{50}$ Hubo un segundo préstamo el 8 de abril de 1866, es decir, que podemos suponer que por esa fecha debió ampliar su negocio. Por un registro de la contribución industrial correspondiente al ejercicio 1867-1868 sabemos que Manuel Malengrete (así aparece escrito) era propietario de una fundición de potes y campanas. ${ }^{51}$ No hay duda de que por esos años se fundían campanas, ya que existe una, datada en 1867, que hoy se encuentra en la iglesia de los P.P. Franciscanos en el Parque de San Lázaro de Ourense. En ella aparece esta inscripción: "Propia de la orden tercera de Penitencia de Orense. Costeado con fondos y limosnas de votos. Padrino de D. José Seijo ministro de la orden. Fábrica de fundición de Orense de Manuel Malingre. Febrero año 1867."

El documento antes mencionado, en el que aparecen diversas fechas de préstamos a Malingre, está datado el 4 de agosto de 1868, y Manuel Malingre Parmentier (el segundo apellido todavía aparece con e, en lugar de Parmantier, como aparecerá en documentación posterior), pide un nuevo préstamo a Donato Hevia Argüelles, con obligación hipotecaria, ante el notario Francisco Cuevas y Cambra. Este préstamo deja sin efecto los anteriores, que combina con este, por el que se obliga a "abonar la mitad de los gananciales que el establecimiento otorga: que se obliga al pago de 1.821 escudos y 739 milésimas y réditos de un $6 \%$ anual cuando le fuesen exigidos, por el señor Parmentier...”. En el mismo documento se refiere que la industria es del matrimonio Malingre-Ludeña, y por ello también comparece para solicitar la hipoteca su mujer, Inés Ludeña Álvarez. ${ }^{52}$

Desconocemos qué ubicación tuvo la primera industria, aunque sí sabemos que en mayo de 1873 la Fundición Malingre ya estaba ubicada en San Lázaro, ${ }^{53}$ donde se celebraba una vez al mes una feria de ganado, motivo por el cual el lugar había sido acondicionado en el año 1857. Era un lugar interesante a efectos comerciales, ya que allí se llevaban a cabo importantes transacciones de especies mulares, porcinas, bovinas, caprinas, equinas y ovinas, lo que atraía a un gran número de comerciantes de toda la provincia. ${ }^{54}$ Se trataba pues de un buen lugar para que Malingre pudiera dar a conocer su producción de hierro.

Según la matricula industrial de 1882, la fundición que Manuel Malingre tiene en San Lázaro tenía cubilotes con una capacidad de $48 \mathrm{~cm}$ cúbicos. ${ }^{55}$ En esta fecha se denomina La Concepción y era un establecimiento de refundición de hierro o

50 AHPO Protocolo notarial de Francisco Cuevas y Cambra, (1868), libro C- 3.185, n. ${ }^{\circ} 211$.

51 AHPO Libro contribución industrial 1867-68 libro 2.483 y contribución (1880-81), libro 2.485 .

52 AHPO Protocolo notarial de Francisco Cuevas y Cambra, año 1868, libro C- 3.185, n. ${ }^{\circ} 211$.

53 AHPO Matrículas industriales. Subsección Hacienda. Libro 2.485.

54 Somoza (2000), p.84.

55 AHPO Subsección Hacienda. Matrículas industriales. Caja 276. 
hierro de segunda fusión. Se puede comprobar que la fundición continúa dada de alta en San Lázaro en las matrículas industriales de los años 1883,1884 y $1885 .^{56}$ Sabemos que la fundición de Malingre en esos años 1884-1885 tenía tarifa $3^{\text {a }}$ de fundidor de hierro en cubilotes en San Lázaro y que pagaba por ella un total de 408,10 ptas. $^{57}$

Son pocos los datos que tenemos sobre la materia prima que usaba y desconocemos los tiempos de trabajo de la fundición. Tenemos noticia a través de un protocolo notarial de la compra de material por parte de Manuel Malingre el 21 de noviembre de 1866. Por el tipo de elementos que compra pensamos que serían para utilizar en la fundición. Se trata de una adquisición de mercancía a cuatro personas: Claudio de Monfancon, Santiago Cherrier, Antonio Baurrens, de nacionalidad francesa, y Robert Juan Valz y Valz, de nacionalidad italiana. Son una serie de objetos que estos poseían como subcontratistas de la vía férrea de Vigo a Ourense, en el tramo Ourense a Barbantes. Entre ellos había mucho material de hierro y también herramientas. ${ }^{58}$ No sabemos la utilidad que pudieran tener para Manuel Malingre, salvo pensar que ese hierro comprado fuera para fundir en segunda fusión en su fundición de hierro.

También sabemos que en 1883 la fábrica se surtía de lingotes de hierro que refundía, llegados a Ourense procedentes de Inglaterra y de Asturias. ${ }^{59}$ Posiblemente estos lingotes llegasen a algún puerto cercano y desde allí los trajeran hasta Ourense. Desconocemos cuál fue el puerto y tampoco sabemos cómo era el transporte, aunque podemos pensar que fuera en carretas.

En 1885 parece que la fundición de Malingre había modificado los proveedores de hierro, empleando lingotes procedentes de Bilbao mezclándolos algunas veces con hierros viejos. ${ }^{60}$

En cuanto al tiempo de trabajo, entre 1887 y 1888 la fábrica La Concepción trabajaba todo el año. ${ }^{61}$ Esto es digno de mención, pues en los boletines de estadísticas mineras podemos ver que muchas fundiciones por esos tiempos trabajan solamente unos determinados meses del año.

56 AHPO Subsección Hacienda. Matrículas industriales. Libro 2.387 y 2.384.

57 AHPO Subsección Hacienda. Matrículas industriales. Libro 2.484.

58 AHPO Protocolo del notario Francisco Cuevas y Cambra de 1866. Libro n. ${ }^{\circ} 3.183$, doc. 281, p. 793-795.

59 Ministerio de Industria. Dirección General de Minas y combustibles (1883), Estadística minera y metalúrgica de España, 1882, Madrid, Consejo de Minería y Metalurgia, p.123.

60 Ministerio de Industria. Dirección General de Minas y combustibles (1886), Estadística minera y metalúrgica de España, 1885, Madrid, Consejo de Minería y Metalurgia, p.123.

61 Ministerio de Industria. Dirección General de Minas y combustibles (1887-88), Estadística minera y metalúrgica de España, 1886, Madrid, Consejo de Minería y Metalurgia, p.193. 
Tenemos pocos datos referentes al personal que trabajó en la fundición. En San Lázaro, y en concreto en el número 1, vivían en el año 1873 dos familias de fundidores, según el censo de habitantes dicha fecha. ${ }^{62}$ Una de esas familias llevaba siete años viviendo en Ourense, según el censo y estaba formada por un padre y su hijo de veinte años, ambos naturales de Boimorto, lugar y parroquia del ayuntamiento de Vilamarín (Ourense). Es posible que trabajasen en la fundición casi desde su apertura en la ciudad. La otra familia solo lleva un año viviendo en la ciudad y estaba formada por un padre y tres hijos, todos naturales de Siero (aunque aparece como una localidad de Lugo, la realidad indica que no existe ninguna población en Lugo con ese nombre y sí, en cambio, en Asturias). Estos fundidores eran Diego Sánchez Fernández, de 46 años y sus hijos, Manuel, Joaquín y José Sánchez Ferrer, de 26, 23 y 18 años respectivamente. Todos estos fundidores fueron con seguridad unos de los primeros trabajadores de la fundición de Manuel Malingre Parmantier, pues era la única que estaba dada de alta en la ciudad en esos momentos. Estos trabajadores fueron probablemente el germen de una nueva clase social, en Ourense, el proletariado industrial.

En 1882 la fundición empleaba ya a 10 hombres y 9 muchachos. ${ }^{63}$ En 1884, la fábrica La Concepción, que sigue siendo la única fundición en Ourense, empleaba a 23 operarios. $^{64}$

Dentro de la dinámica industrial del momento, sabemos que la fundición, siendo una industria incipiente, fue centro de alguna huelga de obreros a finales del siglo xIx. Parece que existió una huelga entre 1888 y fin del siglo en la fundición Malingre, según se puede deducir de los datos conocidos por medio de información oral sobre Valerio Malingre. ${ }^{65}$ Valerio fue hijo de Narciso Malingre Parmentier, hermano de Manuel y por lo tanto su sobrino. Procedente de Vizcaya, comenzó a trabajar en la fundición de su tío y, al parecer, durante una huelga obrera acontecida a finales del xix, apoyó la huelga, poniéndose de parte de los obreros. Este hecho provocó tal malestar familiar que Valerio Malingre tuvo que marchar de Ourense. Estos enfrentamientos y rencillas familiares dieron lugar a que Valerio renegase del apellido Malingre cambiándolo por Malangré, al parecer por el mayor parecido fonético con el original, en francés. No sabemos la fecha exacta del enfrentamiento entre entre tío y sobrino, pero sí que con seguridad fue antes de 1901, ya que en

62 AHPO. Concellos. C-534, año 1873. Santo Domingo. $5^{\circ}$ cuaderno.

63 Dirección General de Agricultura, Industria y Comercio (1882), Estadística minera de España, Madrid, 1883, p. 123.

64 Dirección General de Agricultura, Industria y Comercio (1882), Estadística minera de España, Madrid, 1886, p. 127.

65 Información oral. Informante Ignacio Malangré Lejonagoitia (Pamplona), nieto de Valerio Malangré y bisnieto de Narciso Malingre Parmantier. 
ese año Valerio se casó con Cecilia Orayen en Pamplona, y en su certificado de matrimonio ya aparece como Valerio Malangré, apellido que ha transmitido a sus descendientes.

Lo cierto es que se sabe que hubo una huelga en Ourense 1898, pues en abril de ese año el Gobernador Civil envió una pareja de agentes de orden público a las inmediaciones de la fábrica de fundición de Malingre, para impedir que se ejerciera coacción sobre los operarios que quisieran volver al trabajo. ${ }^{66}$

En cuanto a la producción de la fábrica, sabemos que esta no se limitó fundición de potes y campanas, ya que entre los años 1871 y 1872 también era una industria de tubos de fundición. ${ }^{67} \mathrm{En} 1873$ la industria funde una columna mingitoria que servirá de modelo a las que se coloquen en la ciudad ese mismo año y que tuvo un coste de 50 reales. $^{68}$

También estuvo relacionada con la instalación de fuentes y la traída de aguas. Aunque según Vázquez Vaamonde "gran parte de las tuberías de hierro empleadas en la instalación de traídas de aguas en Galicia, fueron adquiridas en el extranjero en vez de ser fundidas en las fábricas gallegas," ${ }^{69}$ creo que no es ese el caso de Ourense, pues la fundición Malingre produjo tubos y bombas de agua al menos entre 1870 y 1874 , y no hay por qué pensar que no siguiera construyéndolas después. ${ }^{70}$

La construcción de potes fue continua desde su inicio y por los años 80 del XIX, además de estos, fundía también balcones, ${ }^{71}$ chimeneas, verjas, y todo tipo de vasijas. ${ }^{72}$

En el año 1890 Manuel Malingre vendió tubos para la bóveda de la Catedral, bolas de metal para su valla y un canalón para recoger aguas del tejado. ${ }^{73} \mathrm{Y}$ en 1893 fundió para la iglesia de San Munio de Veiga un comulgatorio por 640 reales. ${ }^{74}$

Aunque son pocas las noticas y documentos encontrados hasta la fecha, parece que la Fundición de Malingre fue diversificando su producción, y llegó a realizar todo tipo de objetos: bombas de agua, potes, potas, arados, piezas de jardín como patas de bancos o pies de mesas, jarrones ornamentales para esos jardines, escaleras, co-

66 La Correspondencia Gallega: diario de Pontevedra: año x, n. ${ }^{\circ}$ 2.484, (16, abril.1898), p. 2.

67 AHPO Municipal-Concellos. Caja 70.

68 Vázquez (1995), p. 557.

69 Vázquez (1995), p. 377.

70 BOP Ourense (1879), n. ${ }^{\circ} 131,3$ de diciembre.

71 Ministerio de Industria. Dirección General de Minas y combustibles (1883), Estadística minera y metalúrgica de España, 1882, Madrid, Consejo de Minería y Metalurgia, p.123.

72 Ministerio de Industria. Dirección General de Minas y combustibles (1887-88), Estadística minera y metalúrgica de España, 1886, Madrid, Consejo de Minería y Metalurgia, p.193.

73 Factura de la Fundición La Concepción, no 28. En ACOU 612 cuatro. Del 22 marzo de 1890

74 ADO 13-19.10. 
lumnas y múltiples modelos de barandillas de balcones para las nuevas edificaciones que se levantaban en la ciudad, así como verjas para jardines. ${ }^{75}$

Podemos citar ejemplos de edificios de finales del XIX ornamentados con barandillas o miradores fundidos en la fábrica de San Lázaro: parece que salieron de esta fundición el mirador de la que se conoce como Casa Fábrega (1887), situada en la calle Progreso esquina con Alejandro Outeiriño (antes Cardenal Quiroga y antigua calle de Alba), y el edificio que se conoció en Ourense como ferretería Villanueva (1881), situado en la calle Progreso y que fue vivienda de Francisco Villanueva Lombardero. ${ }^{76}$ Ambas edificaciones fueron proyectadas por Antonio Crespo y ampliadas por José Queralt. ${ }^{77}$ Otras viviendas proyectadas por el arquitecto Antonio Crespo presentan balcones de hierro que son de Malingre: la conocida como Casa de Saco y Arce en la plaza del Trigo, esquina Hernán Cortés, o una vivienda de 1879 situada en la calle Santo Domingo, y hoy desaparecida, cuya imagen podemos ver en una publicación de María Victoria Carballo Calero. ${ }^{78}$ También otras obras de José Queralt están adornadas con balcones de la fundición, como la casa n. ${ }^{\circ} 24$ de la calle Santo Domingo, con hierros de la fundición Malingre del año 1888. Otra casa del año 1889 en la calle Progreso, esquina con Ervedelo, que fue reformada en 1892. También el cierre del seminario, realizado bajo proyecto de Queralt en 1888, o el edificio Simeón, del arquitecto Serra e Pujals del año 1894, ${ }^{79}$ tienen hierros de la fundición Malingre, y un ejemplo digno de mención son sus escaleras de caracol.

Sabemos que en el año 1896 ya fabricaba cocinas de las llamadas "económicas", producto importante en esta fábrica a lo largo de todo el siglo XX. ${ }^{80} \mathrm{O}$ que en 1897 vende tres canalones a la Catedral de Ourense. ${ }^{81}$

Conocemos esta producción antes de finalizar el siglo XIX, época en la que no se guardan muchos datos. Los setenta y nueve años restantes la fundición llevó a cabo muchos más tipos de piezas, pero no pretende este artículo explicar la producción de la fundición en sus 114 años de vida, sino relacionar su origen con los

75 Se pueden conocer algunas de las piezas que salían de la fundición a través de una fotografía de la familia Malingre Ludeña que, en los años 80 del siglo XIX, se fotografía con su producción. Autor de la fotografía Francisco Prieto.

76 Carballo-Calero, (1995), pp. 86-89. Luis Fábrega Coello, propietario de la casa Fábrega y Francisco Villanueva Lombardero, de la ferretería Villanueva. Ambos fueron alcaldes de la ciudad de Ourense.

77 José Antonio Queralt y Antonio Crespo fueron los grandes arquitectos de la época en Ourense, Junto con Daniel Vázquez Gulías, cuyos edificios también embelleció la fundición con sus hierros a principios del siglo XX. Paz, J., en Faro de Vigo, (2019), [en línea].

78 Carballo-Calero, (1995), pp. 95-112.

79 AMO Proyectos. leg.13.

80 El Regional: diario de Lugo, n. ${ }^{\text {o }} 4.922$ (1896, septiembre,15), p. 2

81 ACO 611/2. Cuentas de fábrica de la Catedral de Ourense 1897. 
fundidores de hierro belgas y con la novedad que supuso este tipo de industria en Galicia en el momento de su implantación en Ourense.

La Fundición Malingre no pierde la oportunidad de darse a conocer y contactar con potenciales compradores, en aquella época. Así, acude a diversos eventos en busca de propaganda, prestigio y potenciales mercados, tales como la Exposición Agrícola de Santiago de Compostela en 1875, ${ }^{82}$ o la Exposición Nacional Agrícola Industrial celebrada en Madrid, entre el 1 de junio y el 15 de octubre de 1892, en la que Manuel Malingre formó parte de una comisión nombrada por el gobernador de Ourense para coadyuvar a la exposición. ${ }^{83}$ Malingre en ese mismo año participa, como vocal de la Junta delegada de Ourense, en la Exposición Nacional de Industrias Artísticas e Internacional de Reproducciones, celebrada en Barcelona. ${ }^{84}$ Así mismo, nos consta que la fundición fue premiada con una medalla de plata por sus cocinas económicas, en la Exposición Regional de Lugo de $1896 .{ }^{85}$

\section{Conclusiones}

Tras analizar el origen de la familia del fundador de la Fundición Malingre y profundizar en el conocimiento de sus antepasados, podemos decir que esta familia Malingre se dedica, al menos desde finales del siglo XVIII a la fundición de hierro, fundiendo clavos, que servían, preferentemente, para la industria naval holandesa. Cuando Bélgica pasa a ser un país independiente, esta industria desaparece y los fundidores de aquella zona, que se incorporan al país belga, debido a su experiencia, son requeridos en las fundiciones del sur de Francia. Ese es el caso de Casimir, padre de Manuel Malingre Parmantier, quien en las fundiciones del sur de Francia adquiere la categoría de maestro fundidor. Allí es reclutado por el general Elorza que busca especialistas por diversos países Europeos, para introducir en España las modernas técnicas que ya estaban en boga en la industria del hierro en Europa.

Así llega la familia Malingre Parmantier en 1852 a la Fábrica de Armas de Trubia, industria pionera y en donde se formaron muchos futuros emprendedores. Manuel Malingre de dieciocho años, probablemente llega con su familia y su formación le sirve de aprendizaje de las técnicas más modernas. Tras su estancia en Gijón, cuya situación laboral allí no hemos podido todavía documentar, y hacia el

82 El Diario de Santiago: de intereses materiales, noticias y anuncios, n. ${ }^{\circ} 1.000,(1875$, octubre, 29), p. 2.

83 BOP de Ourense, n. ${ }^{\circ}$ 164, (1891-1892, enero, 9), p. 1.

84 Catálogo de la Exposición Nacional de Industrias artísticas e internacional de reproducciones, Barcelona: Imprenta Hernrich y Cía en comandita, 1892, p. 25.

85 El regional: Diario de Lugo, n. ${ }^{\circ} 4.953$ (1896, octubre, 17), p. 2. 
año 1864 decide instalar una fundición de hierro de segunda fusión en la ciudad de Ourense, aprovechando la futura construcción de la vía férrea al paso por esta ciudad y las crecientes necesidades, por las dinámicas nuevas, de las ciudades burguesas y el mayor uso de herramientas y aperos agrícolas de hierro. La Fundición Malingre, denominada entonces La primera de Orense, una industria moderna para su época, con proyección en el territorio nacional y que aportará mucho especialmente a la ciudad y a la provincia de Ourense durante toda la segunda mitad del siglo XIX, adquiriendo con ello un prestigio que la acompañará a lo largo de sus ciento catorce años de vida. 


\section{Bibliografía}

ALCALÁ-ZAMORA, José, (1974), Historia de una empresa siderúrgica española: los altos hornos de Lierganes y La Cavada, 1622-1834, Diputación Provincial Santander.

ALONSO ÁLVAREZ, Luis, (2005), "La crisis de la economía tradicional: continuidad y cambio en la Galicia del siglo XIX”, en DE JUANA LÓPEZ, Jesús y PRADA RODRÍGUEZ, Julio, (coords.): Historia contemporánea de Galicia, Ariel, Barcelona, pp. 33-55.

ARIAS SARASOLA, Ricardo y SUÁREZ GONZÁLEZ, José Luis, (2008), Historia de la fábrica de cañones de Trubia. La fabricación de acero para tubos de cañones, manguitos, zunchos, corazas y piezas moldeadas, Gráficas Careaga, Asturias.

BAS ORDOÑEZ, Guillermo, (2009-2010), "La arquitectura de la Real Fábrica de Sargadelos," Espacio, tiempo y forma, serie, VII, $\mathrm{H}^{\mathrm{a}}$ del arte, t. 22-23, pp. 275-301.

BILBAO BILBAO, Luis María, (1988), "La primera etapa de la industrialización en el País Vasco 1800-1880: el cambio tecnológico y la estructura de la industria siderúrgica”, en HERNÁNDEZ MARCO, José Luis y FERNÁNDEZ DE PINEDO Emiliano (eds.): La industrialización del Norte de España, Crítica, Barcelona, pp. 222-251.

CARBALlO-CALERO, María Vitoria, (1995), La ciudad de Ourense: el desarrollo urbano (1880-1940), Ayuntamiento, Ourense.

CARMONA BADÍA, Xoán, (1990), "Crisis y transformación de la base industrial gallega 1850-1936”, en NADAL OLLER, Jordi, y CARRERAS ODRIOZOLA, Albert (eds.), Pautas regionales de la industrialización española (s. XIX y XX), Ariel, Barcelona.

CARMONA BADÍA, Xoán, (1993), "Sargadelos en la historia de la siderurgia española," Revista de Historia Industrial, $\mathrm{n}^{\circ}$ 3, pp. 11-40-

CARMONA BADÍA, Xoán y GARCÍA LOMBARDERO, Xaime, (1985), "De la crisis del Antiguo Régimen a la formación de los primeros sectores industriales. Dos puntos de inflexión en la historia contemporánea de Galicia" en Actas de la IX Reunión de Estudios regionales "Crisis, autonomía y desarrollo regional, Asociación española de ciencia regional. Asociación galega de ciencia regional, Universidad de Santiago de Compostela, pp. 433-452.

CARMONA BADÍA, Xoán y NADAL OLLER, Jordi. (2005), El empeño industrial de Galicia. 250 años de historia (1750-2000), Fundación Pedro Barrié de la Maza, La Coruña.

CEBALLOS CUERNO, Carmen, (2002), "Las ferrerías de la Cuenca del río Asón: nuevas aportaciones al estudio de la industria siderúrgica tradicional de Cantabria”, Monte Buciero, 8, pp. 213-244.

DÍAZ GONZÁLEZ, María del Mar y NIEMBro PRIETO, Antonio, (1999), "Les Wallons et líndustrialisation des Asturias: Quatre Linux de mémorie (1833-1983)" en TIELVE GARCÍA, Natalia, (coord.): La Real fábrica de Armas de Trubia: Patrimonio de la industrialización de España, Gijón, Centro de iniciativas culturales CICEES.

DÍEZ ESTÉBANEZ, María Antonia (2013), "Del carbón vegetal al coque en la industria del hierro y del acero", Fundipress. Revista de la Fundición, (36 45), pp.48-53. 
DIRECCIÓN GENERAL DE AGRICULTURA, INDUSTRIA Y COMERCIO. (1882), Estadística minera de España, Madrid.

--_-(1883), Estadística minera de España, Madrid.

-(1885): Estadística minera de España, Madrid.

-(1886): Estadística minera de España, Madrid.

GARCÍA LOMBARDERO, Jaime (1985), "La economía en Galicia entre los años 18001940” en DE JUANA LÓPEZ Jesús. y DE CASTRO, Xavier (Dir.): I Xornadas de Historia de Galicia, Deputación provincial, Ourense, pp. 443-445.

GODECHOT, Jacques, (1981), "La industrialización europea en la época revolucionaria” en VILAR Pierre [et al.], La industrialización Europea. Estadios y tipos, Editorial Crítica, Barcelona, pp.83-106.

LLORDÉN MIÑAMBRES, Moisés, (1994), Desarrollo económico y urbano de Gijón en los siglos XIX y XX, Universidad, Oviedo.

MALINGRE RODRÍGUEZ, Ana María, (2011), "La fundición Malingre de Ourense", Porta da Aira, 13, pp. 225-261.

MATUTE ROYO, Emilio, (2005), "Introducción al diseño industrial en la casa Sancena de Pamplona: 1848-1958”, Huarte de San Juan Geografía e Historia, 12, pp. 277-304.

MARTUL VÁZQUEZ, Purificación y VARELA ZAPATA, Jesús, (2009), "El proyecto y la influencia inglesa en el desarrollo industrial de Sargadelos”, Revista Antropológica, 11, pp.193-204.

PIRENKEMPER, Toni, (2001), La industrialización en el siglo XIX. Revoluciones a debate, Siglo XXI de España editores S.A., Madrid.

SOMOZA MEDINA, José, (2000), "Dinámica industrial de Ourense en el siglo XX", Polígonos, 10, pp.117-133.

STRIKE, James, (2004), De la construcción a los proyectos. La influencia de las nuevas Técnicas en el diseño arquitectónico. 1700-2000, Reverté, Barcelona.

SUÁREZ MENÉNDEZ, Roberto, (1995), "La industria militar española anterior a 1808”, Militaria. Revista de cultura militar, 7, pp. 207-223.

VILLARES PAZ, Ramón y BAHAMONDE MAGRO, Ángel, (2015), El mundo contemporáneo. Del siglo XIX al XXI, Taurus, Barcelona.

\section{Fuentes:}

- Publicaciones periódicas:

El Regional: diario de Lugo, n. ${ }^{\circ} 4.922$ (1896, septiembre, 15).

El Regional: Diario de Lugo, n. ${ }^{\circ} 4.953$ (1896, octubre, 17).

El Diario de Santiago: de intereses materiales, noticias y anuncios, n. ${ }^{\circ} 1.000,(1875$, octubre, 29).

Faro de Vigo, (02-02-2009), OTERO RICART, José Ángel, "Más que un ilustrado, el marqués de Sargadelos era un hombre de acción”, [en línea] https://www.farodevigo.es/sociedadcultura/2009/02/02/ilustrado-marques-sargadelos-hombre-accion/293553.html 
La Correspondencia Gallega: diario de Pontevedra: año x, n. ${ }^{\circ} 2.484$, (16, abril.1898).

La Región, (15-04-2019), PAZ, José, "La fragancia modernista de Gulías", [en línea] https://www. laregion.es/articulo/ourense/fragancia-modernista-gulias/2190414200318866026.html. BOP Ourense, n. ${ }^{\circ} 131,(1879$, diciembre, 3$)$.

BOP de Ourense, n. ${ }^{\circ} 164,(1891-1892$, enero, 9)1.

- Documentos de trabajo:

TASCÓN FERNÁNDEZ, Julio y OJEDA GUTIÉRREZ, Germán (2000), Técnicos y empresarios extranjeros en la industrialización de Asturias. Documentos de trabajo, n. ${ }^{\circ} 221$ [en línea] http://dialnet.unirioja.es/servlet/oaiart?codigo=1253288

Catálogo de la Exposición Nacional de Industrias artísticas e internacional de reproducciones, Barcelona: Imprenta Hernrich y Cía en comandita, 1892, p. 25.

- TESIS DoctoraLEs:

VÁZQUEZ VAAMONDE, María del Carmen, (1995) La metalurgia en Galicia de los siglos XVII al XX. Ferrerias, fundiciones y forjas, Villares, R. (dir.), Universidad de Santiago de Compostela.

- Recursos en línea:

URDANGARÍN ANTUNA, Carmelo e IZAGA REINER, José María, Oficios tradicionales, Diputación Foral de Guipúzcoa [en línea] https://www.gipuzkoa.eus/es/web/ aintzinako-lanbideak/modelistas-fundicion [accesado 23/06/2018].

Blog INSERTEC Blog. Hornos industriales y soluciones refractarias [en línea] https:// www.insertec-store.com/blog/es/horno-cubilote/ [accesado 26-02-2019].

- Archivos:

ARCHIVES DE L'ÉTAT Á MONS, BÉLGICA, Naissances, 1834, n. ${ }^{\circ} 30$.

ARCHIVES MUNICIPIO DE SN. VENANT. PASO DE CALAIS, Francia, Extracto del registro de las actas de fallecimiento, año 1827.

ARCHIVES MUNICIPALES D`ALÈS, FRANCIA, Naissances 1849, CD6, apunte 144, p. 45.

ARCHIVO ECLESIÁSTICO DEL EJÉRCITO DE ESPAÑA, Libro 1201. Folio 35, acta n. ${ }^{\circ} 33$.

ARCHIVO MUNICIPAL DE GIJÓN:

-Registro Civil. Libro de matrimonios de 1857, n 63, p. 38.

-Registro Civil. Libro de nacimientos de 1858, nº 249, p. 134.

ARCHIVO HISTÓRICO PROVINCIAL DE OURENSE. AHPO

-Concellos. C-530. Calle Santo Domingo, 1872.

-Concellos. C-534. Calle Santo Domingo. $5^{\circ}$ cuaderno, 1973. 
-Concellos. Caja 70.

-Libros Industria-Hacienda, n. ${ }^{\circ}$ 2.449, 2.983, 3.000 y 3.001.

-Protocolo notarial de Francisco Cuevas y Cambra, 1866. Libro n. ${ }^{\circ} 3.183$, doc. 281.

-Protocolo notarial de Francisco Cuevas y Cambra, 1868. Libro n. ${ }^{\circ}$ 3.185, doc. 211.

-Subs. Hacienda. Matrículas industriales. Libros 2.387, 2.384, 2.484 y 2.485.

-Subs. Hacienda. Matrículas industriales. Caja 276.

ARCHIVO CATEDRAL DE OURENSE. ACO

-Expediente 612/4. Cuentas de fábrica de la Catedral de Ourense 1890.

-Expediente 611/2. Cuentas de fábrica de la Catedral de Ourense 1897.

ARCHIVO DIOCESANO DE OURENSE. ADO

-Expediente facturas 13-19.10.

ARCHIVO MUNICIPAL DE OURENSE. AMO

-Proyecto de obras. leg.13.

- Otras fuentes:

- Archivo particular de Ricardo Arias Sarasola

-Acta $n .{ }^{\circ} 51$ de la Junta facultativa de la fábrica de Trubia. Sesión de 8 de julio de 1856, fol. n. ${ }^{\circ}$ 154. [Fotocopias del original del Archivo de la fábrica de Trubia]. -Acta n. ${ }^{\circ} 55$ de la Junta facultativa de la fábrica de Trubia. Sesión de 16 de julio de 1852. [Fotocopias del original del Archivo de la fábrica de Trubia].

-Fotocopias que conserva del archivo de la Fábrica de Trubia.

- Archivo particular de la familia Freijanes Malingre

-Fotografía propiedad de la familia Malingre Parmantier. Autor de la fotografía, Francisco Prieto, que fue publicada en SALGADO SÁNCHEZ, Rafael Ángel, (2011), Achegamento a historia da fotografía, Deputación, Ourense, p.64.

-Certificado de bautismo expedido en la parroquia de San Pedro Apóstol de Gijón, el 27 de agosto de 1895 por D. Cipriano Fernández y Robledo. Libro de Bautismos XVII, folio 236.

- Archivo particular de Ana Malingre Rodríguez

-Factura de la venta de 1 dato aparece en un membrete de una factura de Manuel Malingre Ludeña hermanos (1907)

- INFORMANTE

Ignacio Malangré Lejonagoitia (Pamplona), nieto de Valerio Malangré y bisnieto de Narciso Malingre Parmantier, hermano de Manuel Malingre. 


\section{ANEXOS}

\section{ANEXO 1: Acta de Nacimiento de Manuel Malingre Parmantier}

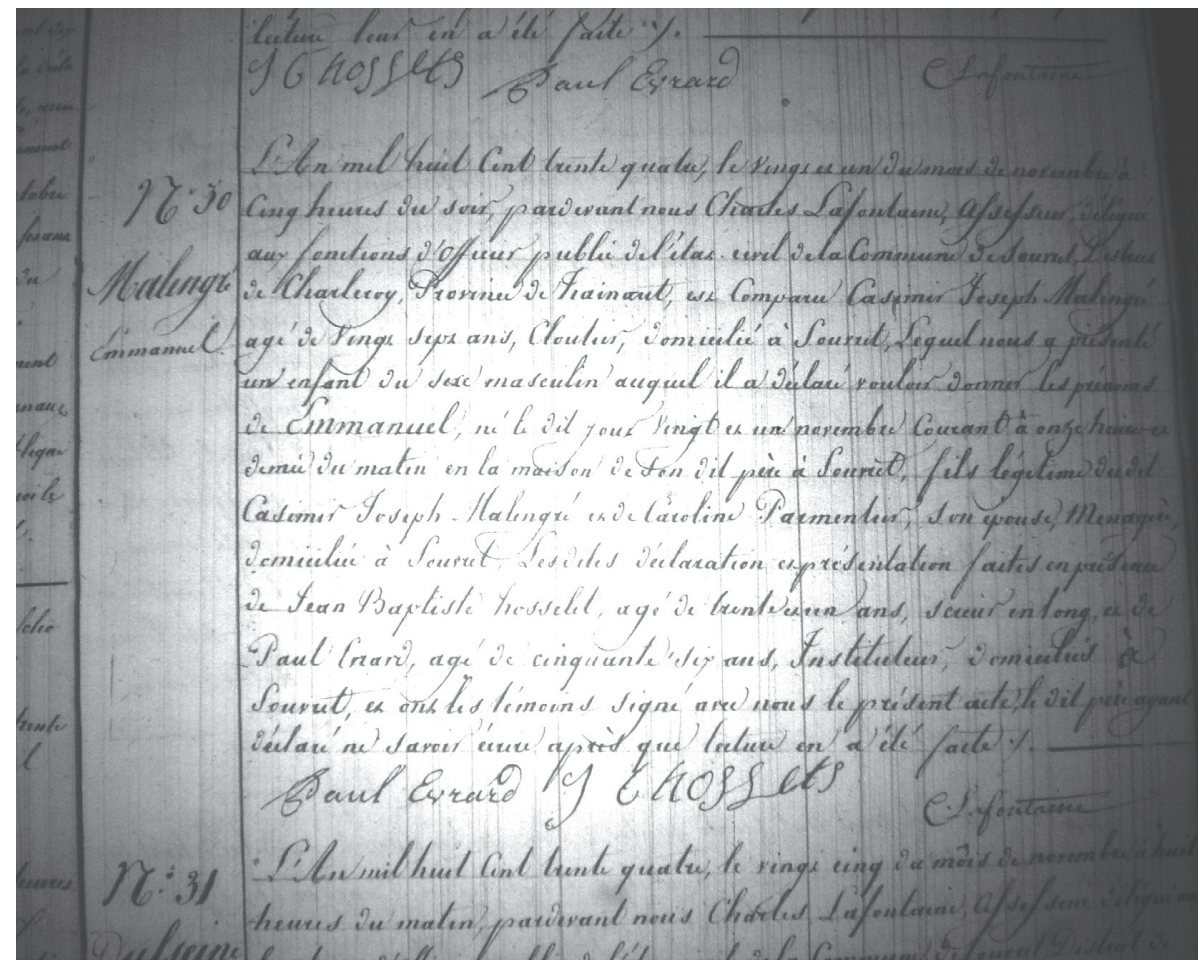

Fuente: Archives de l'État à Mons, Bélgica, Registro de nacimientos, año 1834, n. ${ }^{\circ} 30$. 
ANEXO 2: Acta de defunción de Jacques Malingre, abuelo de Manuel Malingre Parmantier

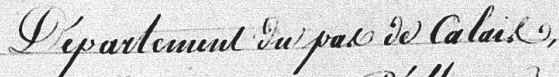 arronidoforment go Aselbune?.}

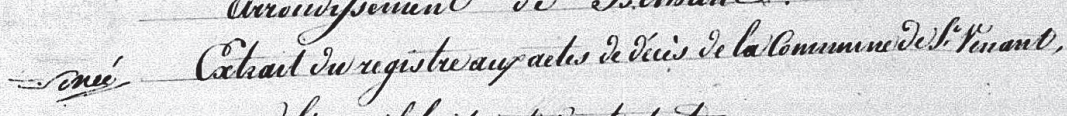

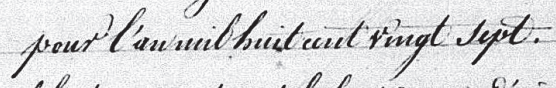

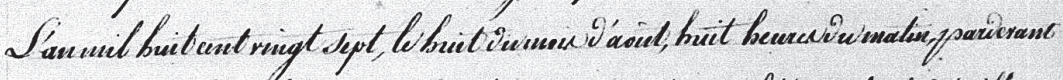

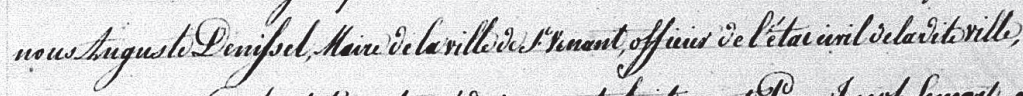

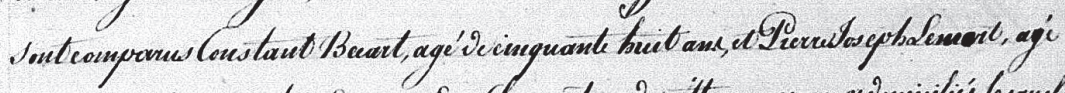

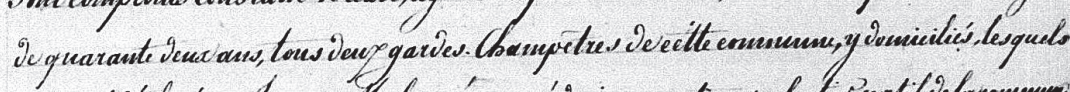

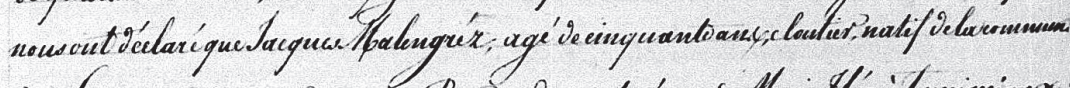

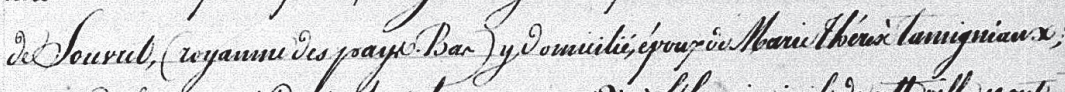

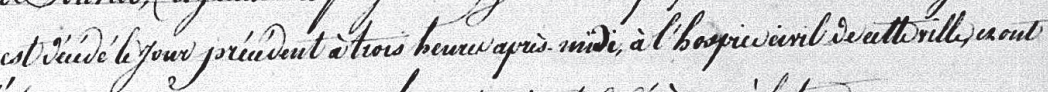

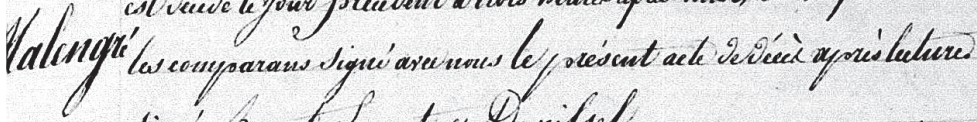

diqne's secart, amarl a tinifoel.

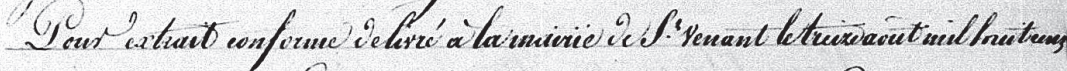

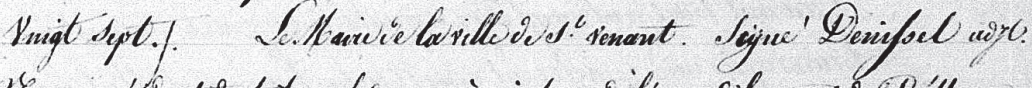

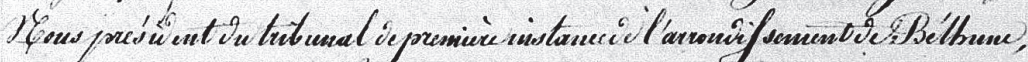

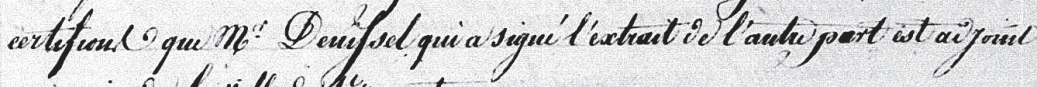

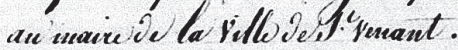

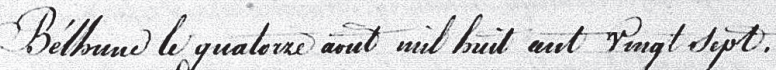
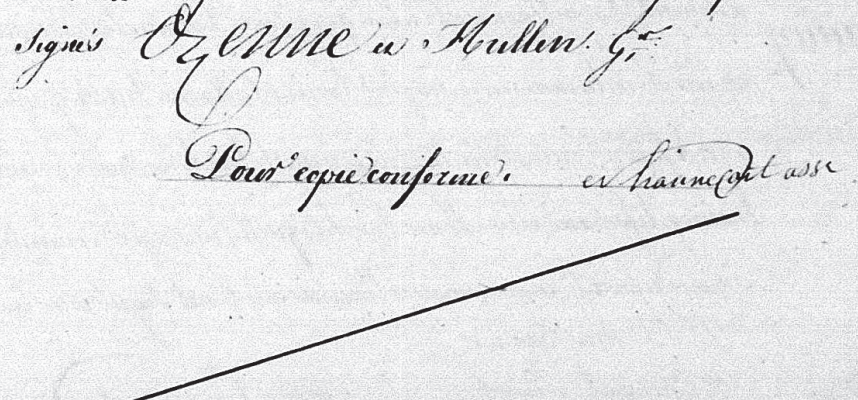

Fuente: Archives municipio de Sn. Venant, Paso de Calais. Francia. Extracto del registro de las actas de fallecimiento 1827. 


\section{ANEXO 2 (Transcripción)}

Departamento del Paso de Calais, partido judicial de Bilhune. EXTRACTO del registro de las actas de fallecimiento del Municipio Sn. Venant para el año mil ochocientos veintisiete. El año mil ochocientos veintisiete, el ocho del mes de agosto a las ocho horas de la mañana ante nos Aguste Denissel alcalde de la Villa de Sn. Venant, oficial del estado civil de la dicha villa, comparecen Constan Becart de 24 años y Pierre Lemort de 42 años ambos guardias campestres de ese partido y nos han declarado que Jacques Malengrez de 50 años, fabricante de clavos natural del partido judicial de Souvret (Reino de los Paises Bajos), y domiciliado, esposo de Marie Terese Taminiaux, falleció el día precedente a las tres de la tarde en el hospicio de esta villa. Los comparecientes firman conmigo el acta de fallecimientos después de su lectura.

Firmados: Becart, Lamort Denissel.

Para extracto conforme de entrega en la alcaldía de Sn. Venant el día 13 de agosto de 1827.

El alcalde de la villa de Sn. Venant firmado Denissel.

Nos presidente del tribunal de primera instancia del partido judicial de Belhume certificamos que mister Denissel que ha firmado el extracto en otra parte, es a día de hoy alcalde de la villa de Sn. Venant.

Belhum 14 de agosto de 1827

Firmado Mullen G.

Para copia conformada (firma poco legible) 


\section{ANEXO 3 a y b: Contrato de trabajo de Casimir Malingre, padre de Manuel Malingre Parmantier en la Fábrica de Armas de Trubia}

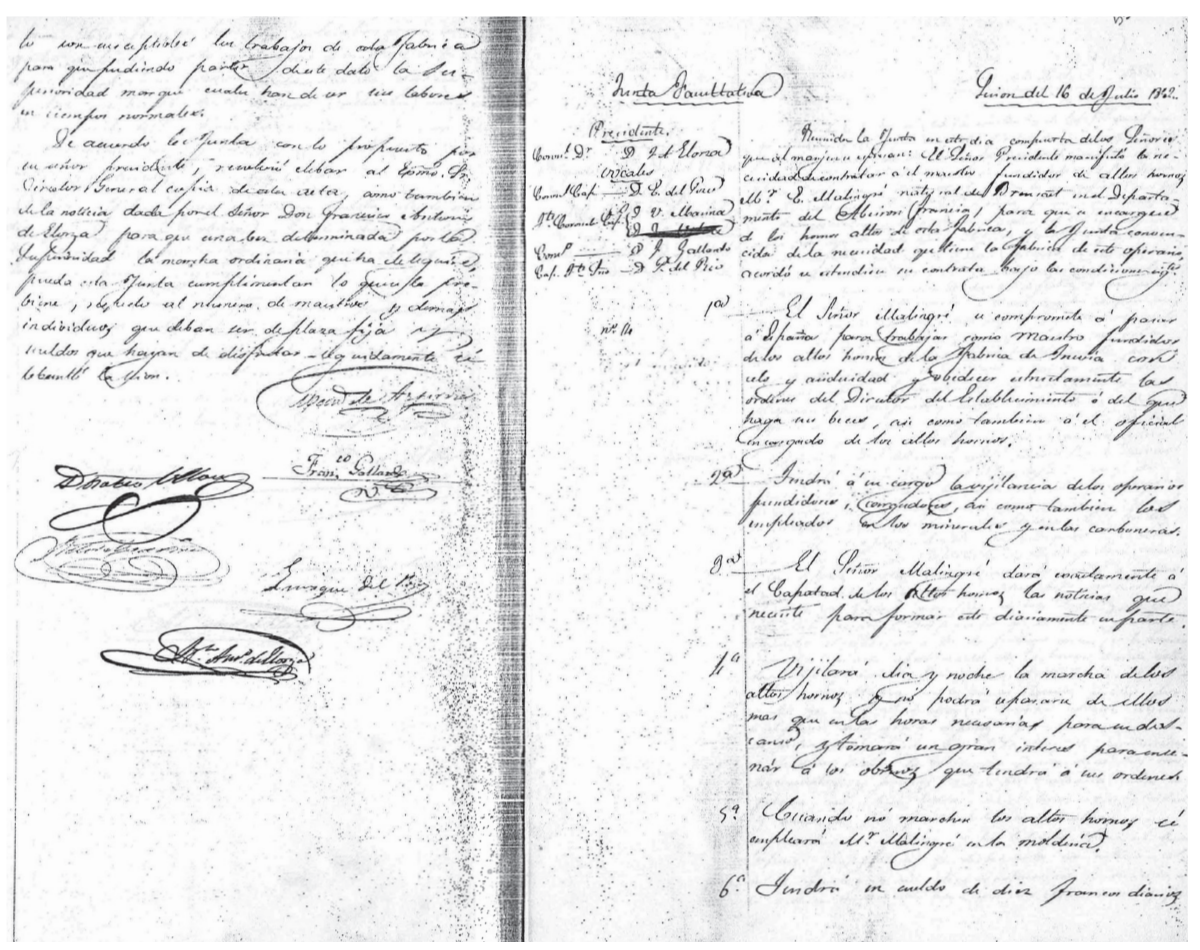

Fuente: Archivo Particular de Ricardo Arias Sarasola. Acta n. ${ }^{0} 55$ de la Junta facultativa de la Fábrica de Armas de Trubia. Sesión de 16 de julio de 1852. [Fotocopias del original del Archivo de la fábrica].

\section{ANEXO 3 a y b. TRANSCRIPCIÓN DEL CONTRATO DE 1852}

Sesión del 16 de Julio de 1852.

Junta Facultativa:

Presidente

Coronel Director. D. A. Elorza

Vocales:

Coronel Cap. D. E del Pozo

Teniente Coronel Cap. V. Marina

Comandante F. Gallardo

Capitán D. P. del Río 
Reunida la Junta en este día compuesta de los Señores que al margen se expresan: el Señor Presidente manifestó la necesidad de contratar al maestro fundidor de altos hornos M. C. Malingré natural de Bramant en el departamento del Abeiron (Francia) para que se encargue de los hornos altos de esta Fábrica, y la Junta convencida de la necesidad que tiene la fábrica de este operario acordó se extendiera su contrata bajo las condiciones siguientes:

$1^{\circ}$ El señor Malingré se compromete a pasar a España para trabajar como Maestro Fundidor de los altos hornos de la Fábrica de Trubia con celo y asiduidad y obedecer estrictamente las órdenes del director del establecimiento o del que haga sus veces, así como también al oficial encargado de los altos hornos.

$2^{\circ}$ Tendrá a su cargo la vigilancia de los operarios fundidores, cargadores, asî como también los empleados en los minerales y en las carboneras.

$3^{\circ}$ El Señor Malingre dará exactamente al Capataz (sic) de los altos hornos las noticias que necesite para formar este diariamente un parte.

$4^{\circ}$ Vigilará día y noche la marcha de los altos hornos y no podrá apartarse de ellos más que en las horas necesarias para un descanso, y tomará un gran interés para enseñar a los obreros que tendrá a sus órdenes.

$5^{\circ}$ Cuando no marchen los altos hornos, se empleará M. Malingré en la moldería.

$6^{\circ}$ Tendrá un sueldo de diez francos diarios o bien 3.650 francos por año, se le abonarán los gastos de viaje, tanto a él como a su familia para venir a España, como también los de regreso a su país, si ha observado buena conducta; además tendrá combustible para la cocina, aceite y muebles para su habitación y en caso de enfermedad, tendrá médico y medicinas para él y su familia.

$7^{\circ}$ El Señor Malingré gozará de un sueldo desde el día que llegue a la Fábrica y tendrá desde el día de su salida de su residencia, cinco francos diarios y lo mismo para su regreso.

$8^{\circ}$ Este contrato durará 4 años a contar desde el día en que se presente en la Fábrica y 3 meses antes de terminarse, se avisarán mutuamente las partes para despedirse o bien para renovar el contrato.

$9^{\circ}$ Este contrato no tendrá efecto hasta que recaiga la aprobación del Excmo. Sr. Director Gral. del Cuerpo.

Firmas:

Francisco Gallardo Pedro del Río

Víctor Marina Enrique del Pozo

Francisco Antonio de Elorza 


\section{ANEXO 4 a y b: Renovación del contrato de trabajo de Casimir Malingre, padre de Manuel Malingre Parmantier en la Fábrica de Armas de Trubia}

$$
\text { Min. } 0.5
$$

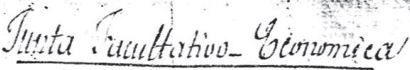
Iesion del Side Iulio delsio

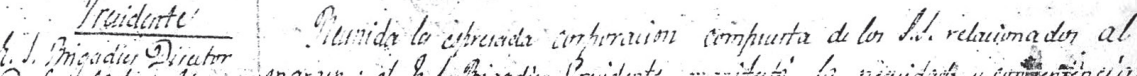

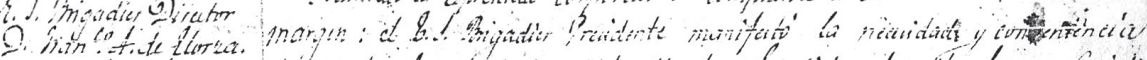

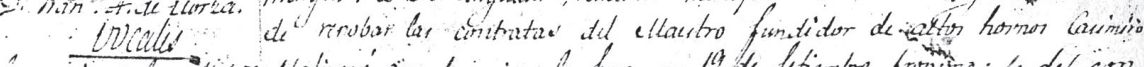

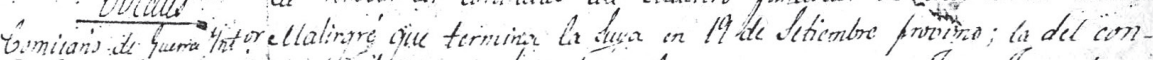

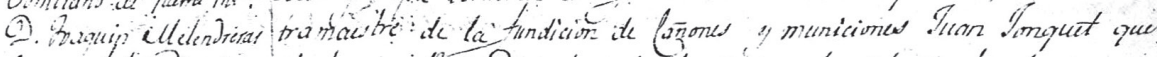

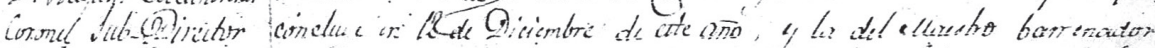

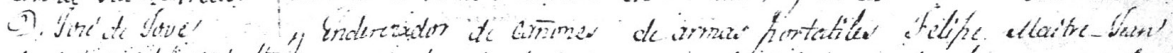

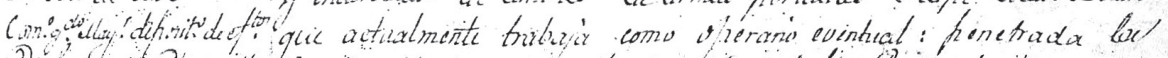

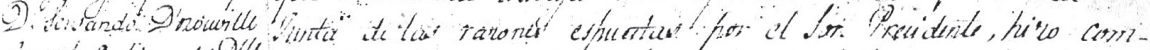

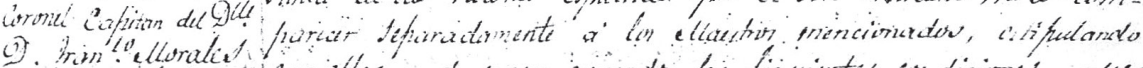

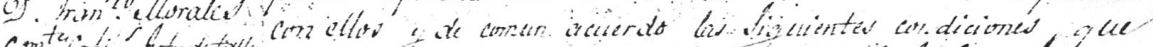

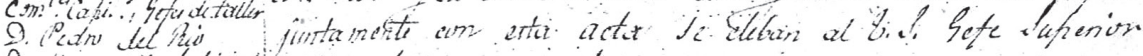

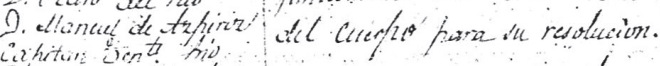

(i) hitur ion mid

Q)

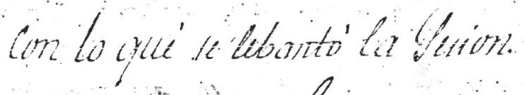

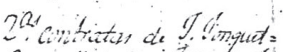

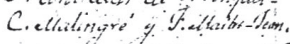

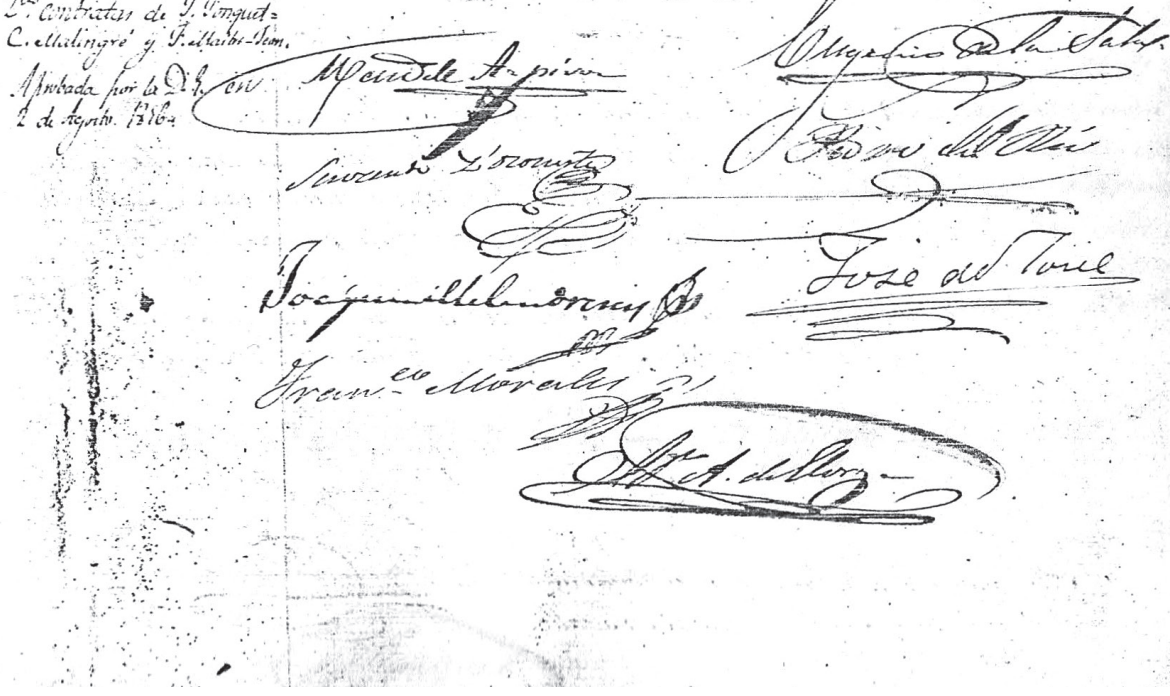




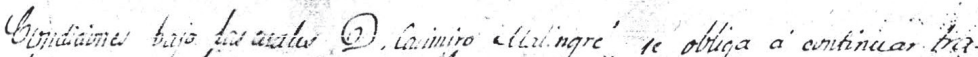

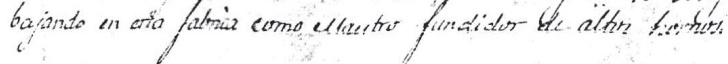

M.

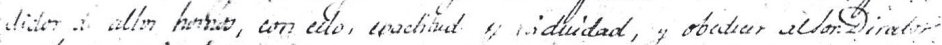

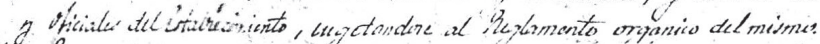

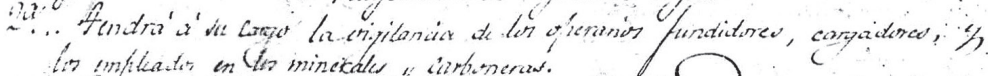

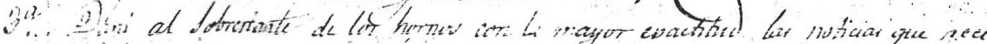
itc Juma citrater at fartit Limio

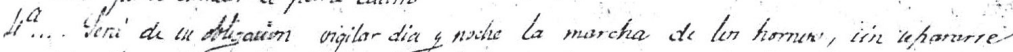

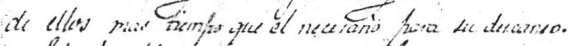

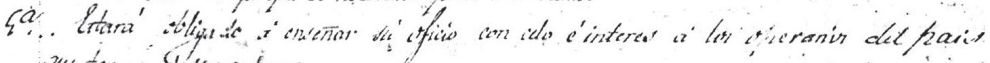
gue teneria sit tue ordence.

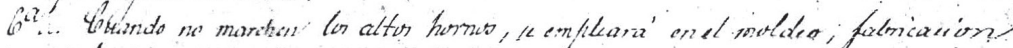

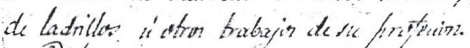

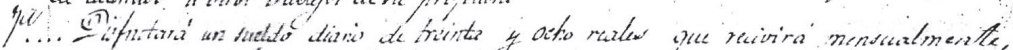

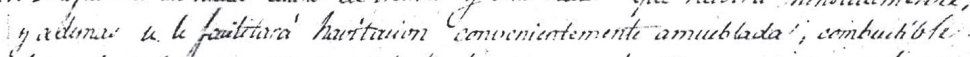

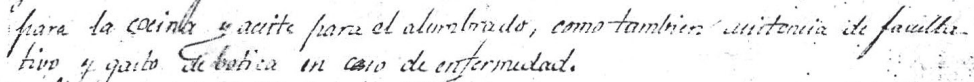

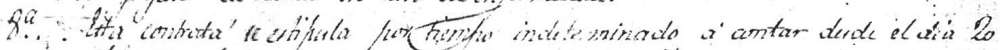

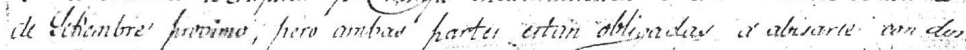

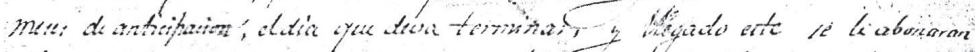

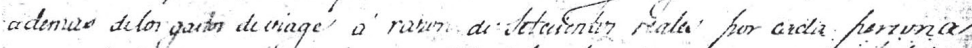

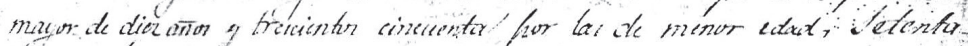

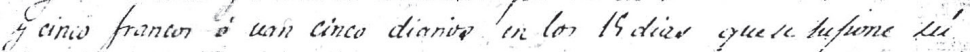
duraciotí.

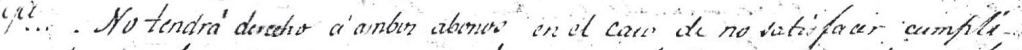

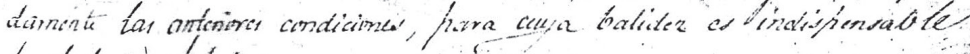

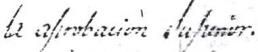

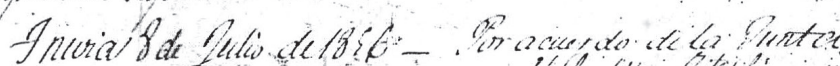

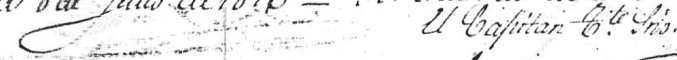

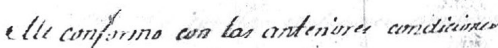

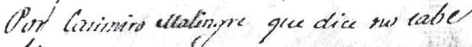
firmar.

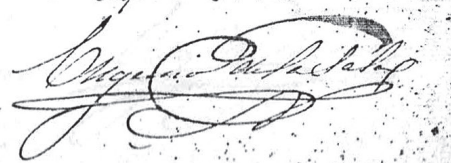

Gelestino Halingre 


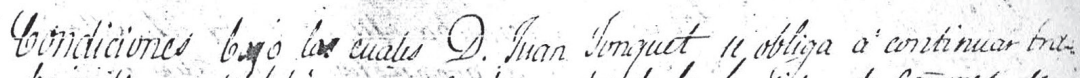

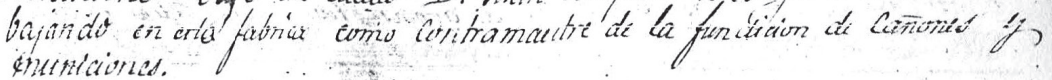

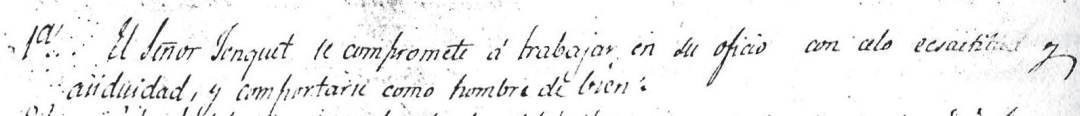

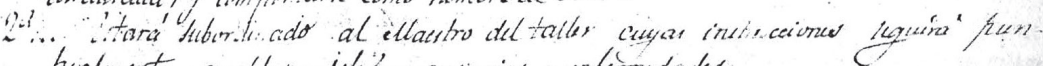

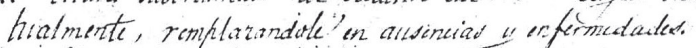

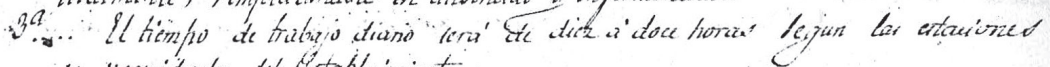

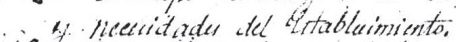

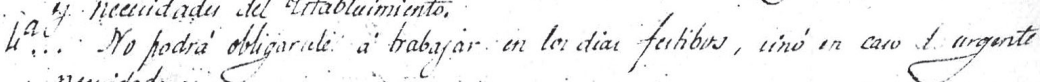
neuridadi. ..

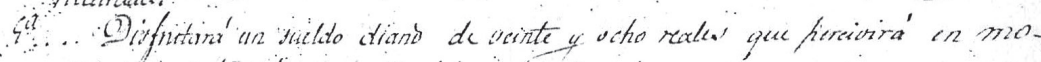

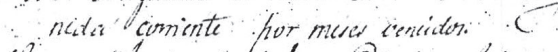

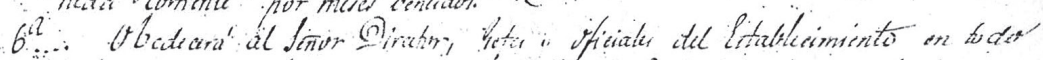

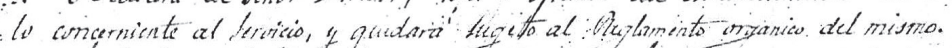

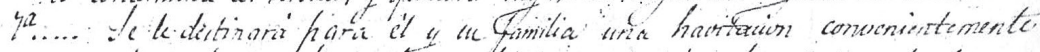

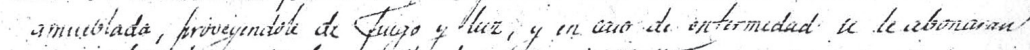

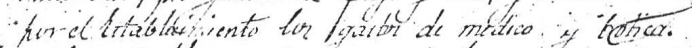

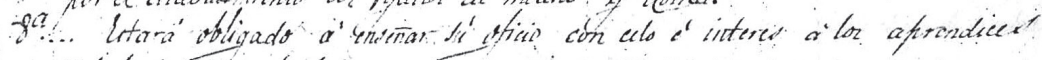

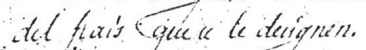

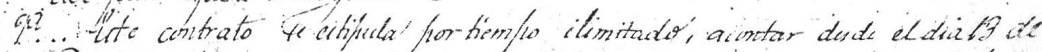

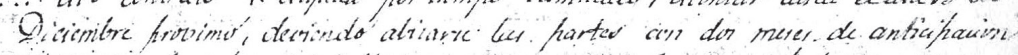

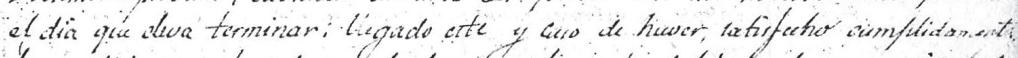

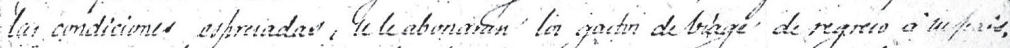

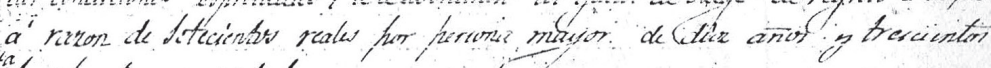
int far far lar de mente eded.

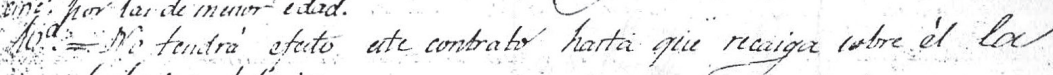
*. cefrithecion lufienion.

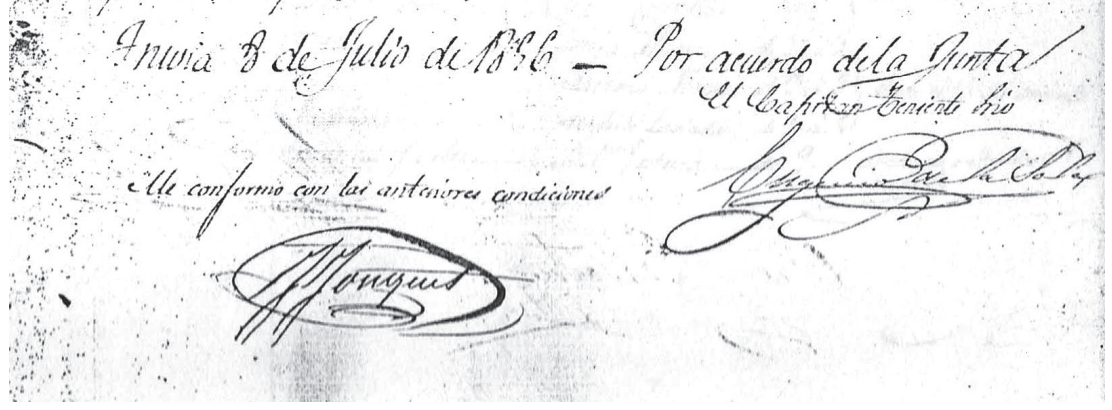

Fuente: Archivo particular de Ricardo Arias Sarasola. Acta n. 51 de la Junta facultativa de la Fábrica de Armas de Trubia. Sesión de 8 de julio de 1856, fol. n. ${ }^{\circ}$ 154. [Fotocopia del original del Archivo de la fábrica]. 


\section{ANEXO 4 a y b (Transcripción)}

\section{Condiciones bajo las cuales D. Casimiro Malingré se obliga a continuar trabajando en esta fábrica como Maestro fundidor de altos hornos}

$1^{a}$ D. Casimiro Malingré se obliga a seguir trabajando en la fábrica como Maestro fundidor de Altos Hornos con celo, exactitud y asiduidad y obedecer al Sr. Director y oficiales del establecimiento, sujetándose al Reglamento orgánico del mismo.

2a Tendrá a su cargo la vigilancia de los operarios fundidores, cargadores y los empleados en los minerales y carboneras.

$3^{\text {a }}$ Dará al sobrestante de los hornos con la mayor exactitud las noticias que necesite para extender el parte diario

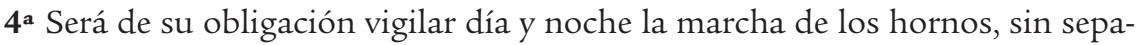
rarse de ellos más tiempo que el necesario para su descanso.

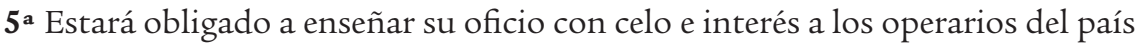
que tenga a sus órdenes.

6 $^{\mathbf{a}}$ Cuando no marchen los altos hornos, se empleará en el moldeo, fabricación de ladrillos u otros trabajos de su profesión.

$7^{\text {a }}$ Disfrutará un sueldo diario de treinta y ocho reales que recibirá mensualmente y además se le facilitará habitación convenientemente amueblada, combustible para la cocina y aceite para el alumbrado, como también asistencia de facultativo y gasto de botica en caso de enfermedad.

$8^{\text {a }}$ Esta contrata se estipula por tiempo indeterminado a contar desde el día 20 de septiembre próximo, pero ambas partes están obligadas a avisarse con dos meses de anticipación, el día que deba terminar y llegado este se le abonarán además de los gastos de viaje, a razón de setecientos reales por cada persona mayor de diez años y trescientos cincuenta por las de menor edad, setenta y cinco francos o sea cinco diarios en los 15 días que se supone su duración.

9a No tendrá derecho a ambos abonos en el caso de no satisfacer completamente las anteriores condiciones, para cuya validez es indispensable la aprobación Superior.

Trubia 8 de julio de $1856 \quad$ Por acuerdo de la Junta

El Capitán Teniente

Eugenio de las Salas

Me conformo con las anteriores condiciones, Por Casimiro Malingre que dice no saber firmar.

Celestino Malingre 


\section{ANEXO 5: Acta de defunción de Casimir Malingre, padre de Manuel Malingre Parmantier}

LIBRO 1201
FOLIO $\quad 35$

ARCHIVO ECLESIÁSTICO

DIAPER-PQ Moret, 3

28008 MADRID

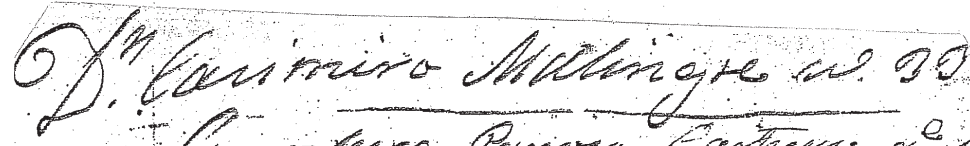

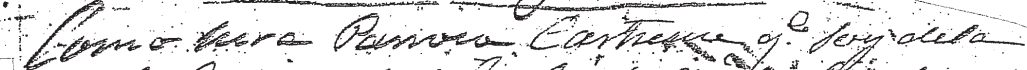

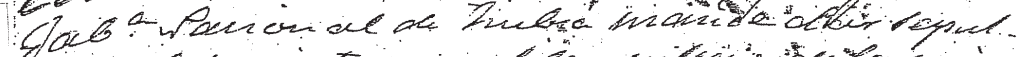

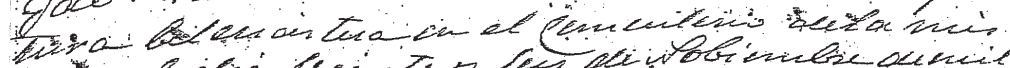

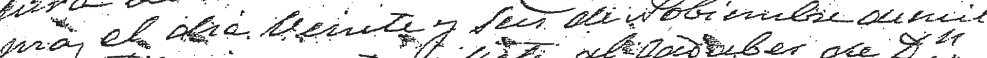

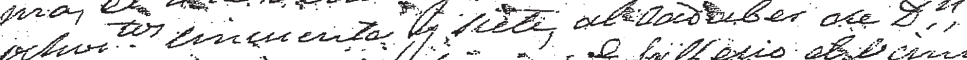

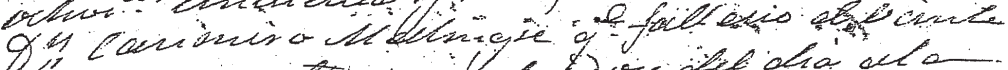

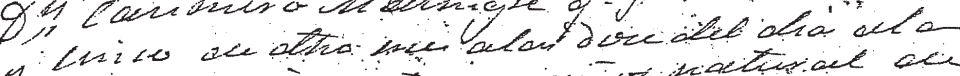

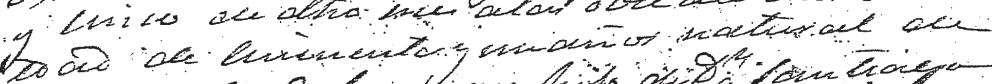

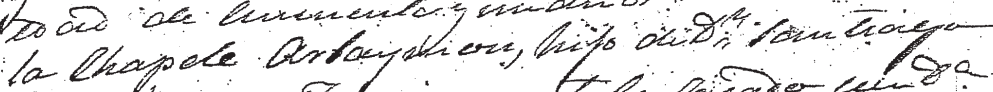

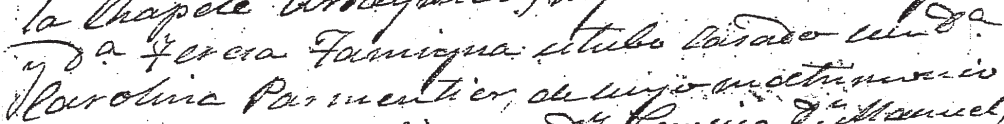

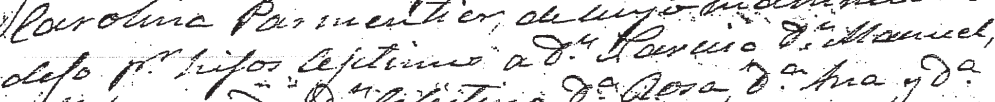

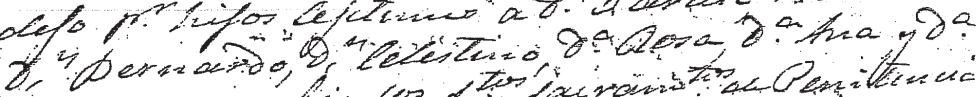

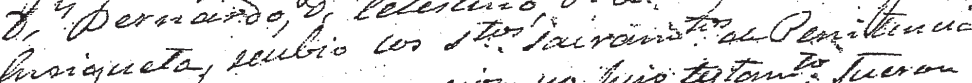

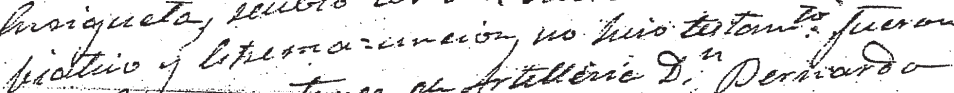

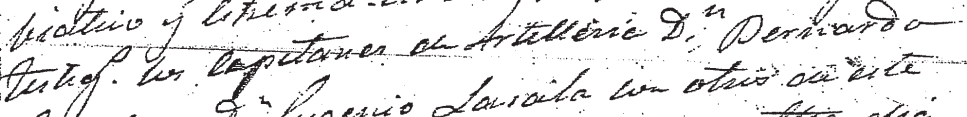

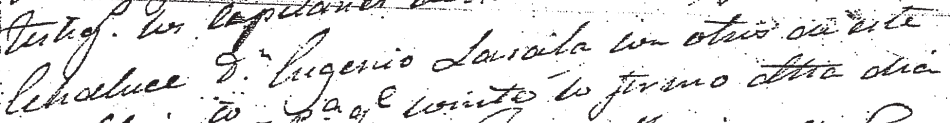

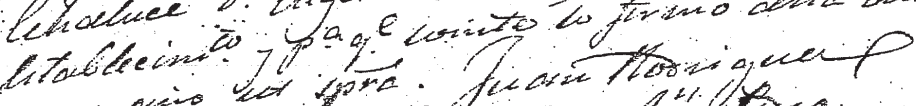

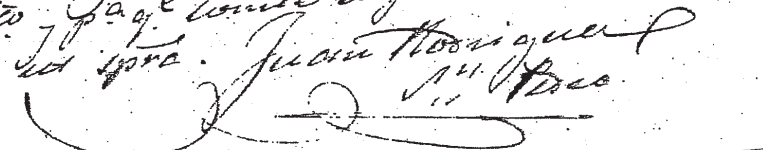

ES FIEL FOTOCOPIA DEL ORIGINAL Medrid, 18 NOV. 2014

EL CAPELLAN JEFE DEL ARCHIVO

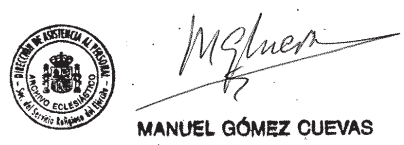

Fuente: Archivo Eclesiástico del Ejército. Libro 1201. Folio 35. Acta n. ${ }^{\circ} 33$. 


\section{ANEXO 5 (Transcripción)}

Archivo Eclesiástico del Ejército

Libro 1201

Folio 35

$\mathrm{D}^{\mathrm{n}}$ Casimiro Malingre $\mathrm{N}^{\mathrm{o}} 33$ (Acta)

Como Cura Párroco Castrense que soy de la Fábrica Nacional de Trubia, mandé dar sepultura cristiana en el cementerio de la misma el día 26 de noviembre de 1857 al cadaber (sic) de $\mathrm{D}^{\mathrm{n}}$ Casimiro Malingre, que falleció el 25 de dicho mes a las doce del día, a la edad de cincuenta y un años, natural de Chapele Arlaymion, hijo de $\mathrm{D}^{\mathrm{n}}$ Santiago y $\mathrm{D}^{\mathrm{a}}$ Teresa Tamigna. Estubo (sic) casado con $\mathrm{D}^{\mathrm{a}}$ Carolina Parmentier, de cuyo matrimonio dejó por hijos legítimos a $\mathrm{D}^{\mathrm{n}}$ Narciso, $\mathrm{D}^{\mathrm{n}}$ Manuel, $\mathrm{D}^{\mathrm{n}}$ Bernardo, $\mathrm{D}^{\mathrm{n}}$ Celestino, $\mathrm{D}^{\mathrm{a}}$ Rosa, $\mathrm{D}^{\mathrm{a}}$ Ana y $\mathrm{D}^{\mathrm{a}}$ Enriqueta. Recibió los Santos Sacramentos de Penitencia, Viático y Estremaunción (sic). No hizo testamento. Fueron testigos los Capitanes de Artillería $\mathrm{D}^{\mathrm{n}}$ Bernardo Echaluce, $\mathrm{D}^{\mathrm{n}}$ Eugenio LaSala con otros de este Establecimiento. Y para que conste lo firmo dicho día, mes y año ut supra.

Juan Rodríguez

San Pedro (¿de Trubia?) 